\title{
EchoGéo
}

$50 \mid 2019$

Varia

\section{Aspects de météopathologie des conjonctivites en phase hiverno-printanière à Sfax (Centre-Est de la Tunisie)}

Mounir Jarraya

\section{CpenEdition}

Journals

Édition électronique

URL : https://journals.openedition.org/echogeo/18296

DOI : 10.4000/echogeo.18296

ISSN : 1963-1197

Éditeur

Pôle de recherche pour l'organisation et la diffusion de l'information géographique (CNRS UMR 8586)

Référence électronique

Mounir Jarraya, «Aspects de météopathologie des conjonctivites en phase hiverno-printanière à Sfax (Centre-Est de la Tunisie) », EchoGéo [En ligne], 50 | 2019, mis en ligne le 31 décembre 2019, consulté le 31 juillet 2021. URL : http://journals.openedition.org/echogeo/18296 ; DOI : https://doi.org/ 10.4000/echogeo.18296

Ce document a été généré automatiquement le 31 juillet 2021.

EchoGéo est mis à disposition selon les termes de la licence Creative Commons Attribution - Pas d'Utilisation Commerciale - Pas de Modification 4.0 International (CC BY-NC-ND) 


\title{
Aspects de météopathologie des conjonctivites en phase hiverno- printanière à Sfax (Centre-Est de la Tunisie)
}

\author{
Mounir Jarraya
}

\section{Introduction}

1 Le contexte climatique influence fortement le bien-être et la santé des individus. Des altérations d'origines multiples, dont le climat, peuvent affecter l'organisme humain et provoquer des maladies. En effet, l'organisme est soumis en permanence aux effets de l'environnement atmosphérique extérieur avec lequel il interagit. Plusieurs études ont mis l'accent sur l'influence du climat sur certaines maladies infectieuses et chroniques (Dowell, 2001; Mäkinen et al., 2009; Tang, 2009). À chaque saison correspond un paysage épidémiologique marqué par la prédominance de certaines affections. À Sfax, plusieurs recherches ont déterminé les impacts du contexte climatique saisonnier sur la fréquence de certaines maladies (Jarraya, 2012 ; Jarraya et Beltrando, 2015 ; Jarraya, 2016 ; Jarraya, 2017 Jarraya, 2018a). L'influence du contexte climatique sfaxien sur les maladies infectieuses nous a incités à analyser le lien qui existe entre le climat et les conjonctivites, d'autant plus que cette question n'a pas été soulevée à Sfax. Ceci en revenant à la définition de la conjonctivite, qui correspond à «l'inflammation ou à l'irritation de la conjonctive de l'œil qui constitue la membrane qui recouvre le blanc de celui-ci et le dessous des paupière " (Leonardi et al., 2014). La symptomatologie des conjonctivites est très variée: des yeux rouges, des brûlures, des paupières collées, larmoiements, démangeaisons et impression de sable sous la paupière (Dalibon, 2014). Cette maladie peut être d'origine infectieuse (bactérienne ou virale) ou se produire également suite à une allergie, par exemple, quand l'œil s'expose à des allergènes présents dans l'atmosphère (Fedaoui et al., 2017). Bien qu'elle soit bénigne, la conjonctivite est une maladie contagieuse et constitue une source de gêne et de 
souffrance en particulier pour les nourrissons. Elle représente également une cause d'absentéisme pour les élèves et les adultes qui travaillent, puisque cette maladie est contagieuse.

2 En agissant sur l'activité des agents infectieux ou en conditionnant la concentration et la dispersion des allergènes dans l'air, l'environnement atmosphérique par ses caractéristiques thermo-hygrométriques et de sa contenue aérobiologique, explique en quelque sorte un paysage épidémiologique changeant durant la phase hivernoprintanière (Thibaudon et al., 2005 ; Laaidi et al., 2011).

3 Le rapport probable entre le contexte climatique et la fréquence des conjonctivites à Sfax trouve sa justification dans des données épidémiologiques, qui permettent de quantifier la maladie (nombre de malades) et le niveau de sa propagation au sein d'une population donnée et à un moment bien déterminé (Jammal et al., 1988), et ce en fonction des consultations médicales effectuées pour conjonctivites dans les Centres de Santé de Base (CSB) à Sfax.

4 Sfax est une grande ville considérée comme une métropole régionale, qui se situe sur le littorale Est de la Tunisie (illustration 1). Composée de six délégations, son agglomération abrite 700000 habitants environ (INS, 2014). Elle se caractérise par une polyvalence économique: une agriculture développée occupant l'arrière-pays de l'agglomération, un tissu industriel diversifié profitant de sa localisation côtière (Karray, 1996) ainsi qu'un secteur tertiaire important abritant des services plus ou moins "rares" exerçant une polarisation spatiale sur les régions environnantes (Fakhfakh, 2000).

Ilustration 1 - Pourcentage des consultations pour conjonctivites du total par délégation à Sfax, de 2003 à 2015

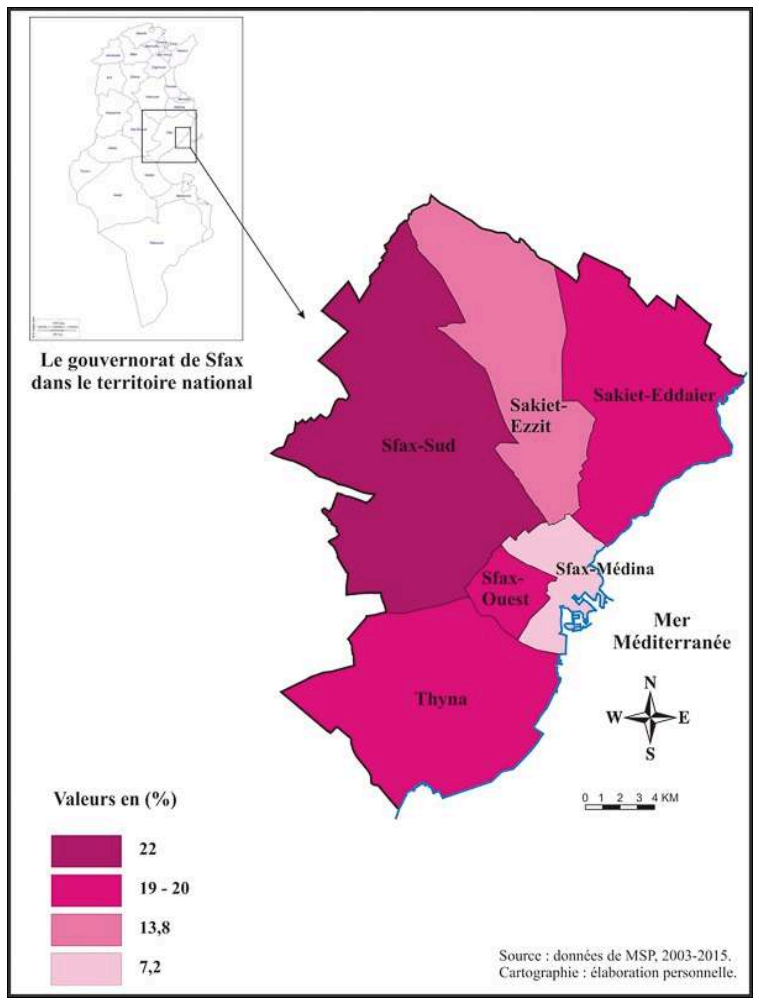

Sources : données MSP, 2003-2015. Auteur : M. Jarraya. 
5 L'infrastructure hospitalière s'est consolidée depuis l'indépendance par deux Centres Hospitalo-Universitaires ( $\mathrm{CHU}$ ) occupant le sommet du système sanitaire public tunisien. Elle constitue par conséquent l'apanage de l'agglomération de Sfax (Jarraya, 2009), où un réseau de Centres de Santé de Base (appelés aussi dispensaires) dispersés dans l'espace de la ville est mis en place pour offrir les soins primaires (la consultation médicale généraliste) à la population (Jarraya et Beltrando, 2013). C'est dans ces 29 dispensaires que la morbidité liée aux diverses maladies est enregistrée quotidiennement à Sfax. Selon les données du Ministère de la Santé Publique, la conjonctivite touche aussi bien les enfants que les adultes. Selon les classes d'âge utilisées, il ressort de notre analyse que les classes $\leq 14$ ans et $\geq 25$ ans représentent respectivement $36,2 \%$ et $45,5 \%$ de l'effectif annuel moyen des consultations pour conjonctivites (9372 cas) sur la période 2003-2015. Dans ce même contexte de répartition des consultations, nous suggérons qu'il soit indispensable de spatialiser la morbidité enregistrée dans l'agglomération de Sfax. En effet, le calcul de la part moyenne de chaque délégation dans l'effectif total des consultations pour conjonctivites montre que Sfax-Sud et Sakiet-Eddaier enregistrent respectivement $22 \%$ et $20 \%$ contre 7,2 \% à Sfax-Médina sur la période 2003-2015 (illustration 1). Par ailleurs, notre objectif est d'analyser la variation temporelle de la morbidité durant la phase hiverno-printanière en mettant l'accent sur son éventuelle interaction avec le contexte thermique à Sfax.

6 L'observation des données de consultations pour conjonctivites à Sfax a permis de souligner un accroissement de sa morbidité durant l'hiver pour atteindre son niveau maximal au printemps. Entre recrudescence hivernale et bouffée printanière, cette morbidité a connu un contexte thermique contrasté durant cette phase. Un contexte climatique 医 instaurant une fraîcheur hivernale et une douceur printanière et favorisant une hausse variable des consultations pour conjonctivites 㹂 qui mérite d'être appréhendé. Il s'agit donc d'étudier l'état thermique changeant à Sfax, afin d'expliquer l'accroissement accéléré de cette morbidité entre l'hiver et le printemps. Par conséquent, notre analyse repose sur la séparation de la phase hivernale de la phase printanière. Une séparation justifiée par les différences au niveau thermique et au niveau de la typologie prédominante des conjonctivites entre les deux saisons, qui permet de mieux élucider les aspects climato-pathologiques intrinsèques pendant cette phase hiverno-printanière. Enfin, si nous avons choisi de ne pas étudier la phase automnale, c'est parce qu'elle présente un pic de morbidité liée aux conjonctivites moins important, qui fera l'objet d'une future étude approfondie.

\section{Données et méthodes}

7 Notre analyse repose sur deux types de données couvrant la période 2003-2015 : d'une part, les données météorologiques moyennes quotidiennes de la température, de l'humidité relative de l'air sous abri, de la vitesse et la direction du vent mesurées à la station synoptique Sfax El-Maou et obtenues de l'Institut National de la Météorologie (INM) ; d'autre part, les données épidémiologiques concernant le nombre quotidien des consultations pour conjonctivites enregistrées par les CSB. Ces données sont obtenues auprès du Ministère de la Santé Publique (MSP). Dans l'agglomération de Sfax, $60 \%$ de la population totale fréquente ces structures de soins publiques primaires (Ben Jemaâ, 2004 ; Jarraya, 2009). À cause du refus des médecins de libre pratique de nous 
transmettre des données, nous étions obligés de travailler uniquement sur les patients qui fréquentent les structures de soins publics (les CSB).

8 L'éventuel rapport entre l'environnement atmosphérique et la morbidité liée aux conjonctivites nous a conduits à adopter une méthode reposant tout d'abord, sur la définition des jours les plus frais en hiver et les plus doux au printemps et sur l'étude de leur fréquence. En effet, la température moyenne est calculée à partir de huit mesures tri-horaires en 24 heures. Compte tenu des niveaux élevés de la morbidité liée aux conjonctivites enregistrée en hiver, nous mettrons en question l'éventuel effet de la fraîcheur sur une telle situation épidémiologique. Nous diagnostiquerons à travers des exemples illustratifs, des situations atmosphériques hivernales associées à une fraîcheur intense et potentiellement favorables à la propagation des conjonctivites. Pour ce faire, nous avons calculé l'écart thermique par rapport à la température mensuelle des mois hivernaux (janvier, février et décembre) et nous avons considéré les écarts négatifs comme coïncidant aux jours froids quel que soit l'ampleur de la fraîcheur. Cela nous a servi pour analyser leurs répercussions sur les consultations pour conjonctivites. Au printemps, nous avons adopté la même démarche, mais en sélectionnant les jours qui enregistrent des écarts thermiques positifs par rapport à la moyenne mensuelle des mois printaniers (mars, avril et mai). Ces jours sont considérés comme des jours doux. Etant justifiée par la recrudescence notable de la morbidité liée aux conjonctivites plus particulièrement en mars et en avril, cette démarche s'attache à démontrer l'effet de la douceur thermique, durant cette période, sur cette morbidité élevée. L'analyse de l'intensification de la douceur permet de déterminer son impact sur la morbidité liée aux conjonctivites au printemps. L'objectif serait d'abord, de dégager le rapport qui existe entre le contexte thermique et les niveaux de morbidité liée aux conjonctivites, à l'échelle moyenne de la période 2003-2015; ensuite, de souligner quelques aspects météopathologiques hivernaux et printaniers liés à l'évolution de la situation thermique en nous référant à des cas pris à titre illustratif (janvier 2012 et avril 2003 et 2012); enfin de déterminer certaines situations atmosphériques associées à l'augmentation des consultations pour conjonctivites durant ces deux saisons à Sfax.

Compte tenu de la complexité de la corrélation météorologique-morbidité à l'échelle journalière, nous nous sommes basés sur deux situations hivernales (10-11 et 29-30 janvier 2012) et deux autres printanières (27-30 avril 2003 et 22-25 avril 2012). En effet, le choix des deux situations hivernales a pour but de mettre en question la sensibilité des types de conjonctivites envers une fraîcheur sèche ou humide conditionnée par des conditions atmosphériques différentes. La même démarche a été appliquée pour avril 2003 et 2012, où nous avons déterminé l'impact de la tendance à la douceur sur les consultations pour conjonctivites. Si les amplitudes thermiques journalières ont été calculées durant ces séquences, c'est dans le but de déterminer l'ampleur des contrastes au niveau de la température de l'air au cours de la journée et par conséquent, leurs éventuelles répercussions sur la morbidité. Afin d'élucider l'impact du contexte climatique sur la fréquence de la morbidité liée aux conjonctivites en avril ainsi que leur perception par les individus, nous avons mené une enquête durant 10 jours (du 6 au16 avril 2015) dans dix CSB (1 jour dans chaque CSB) (illustration 2). Nous avons cherché une meilleure représentativité des différents secteurs de l'agglomération de Sfax lors de leur choix. L'effectif des personnes interrogées est de l'ordre de 114 cas. Celui-ci correspond au nombre des personnes 
consultant dans les CSB pour asthme. Nous notons que la conjonctivite constitue un symptôme permanent pour la quasi-totalité de ces patients. Un questionnaire a été élaboré pour fournir des informations, se rapportant non seulement aux aspects météopathologiques des conjonctivites et à la vulnérabilité de la population, mais aussi au contexte socio-environnemental susceptible de favoriser l'affection (Jarraya, 2018b). En outre, nous avons effectué des entretiens avec les médecins en postes dans les CSB, des ophtalmologues et des pneumologues-allergologues pratiquant dans le secteur sanitaire public et privé, pour comprendre la variation du paysage épidémiologique des conjonctivites et déterminer le type prédominant, la nature de l'agent responsable de l'affection durant la phase étudiée, sa symptomatologie ainsi que ses aspects météopathologiques.

Illustration 2 - Réseau des CSB concernés par l'enquête dans l'agglomération de Sfax (6-16 avril 2015)

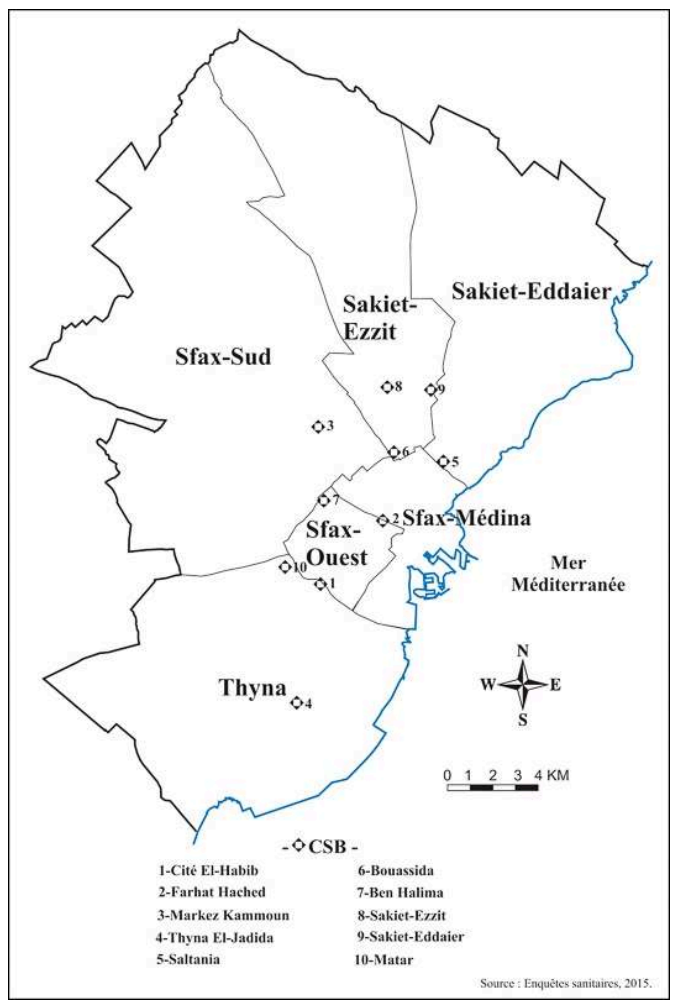

Sources : enquête sanitaire, 2015. Auteur : M. Jarraya

\section{D'une recrudescence hivernale...}

La morbidité liée aux conjonctivites est prédominante en hiver car elle augmente régulièrement de 586 cas en décembre à 732 cas en février sur la période 2003-2015 (illustration 3). Cet accroissement de $25 \%$ entre ces deux mois permet de suggérer un effet potentiel de l'environnement atmosphérique sur sa fréquence à Sfax. Nous diagnostiquons les spécificités thermiques hivernales, afin de déterminer éventuellement leurs impacts potentiels sur la morbidité. 
Illustration 3 - Variation des consultations moyennes mensuelles pour conjonctivites à Sfax (2003-2015)

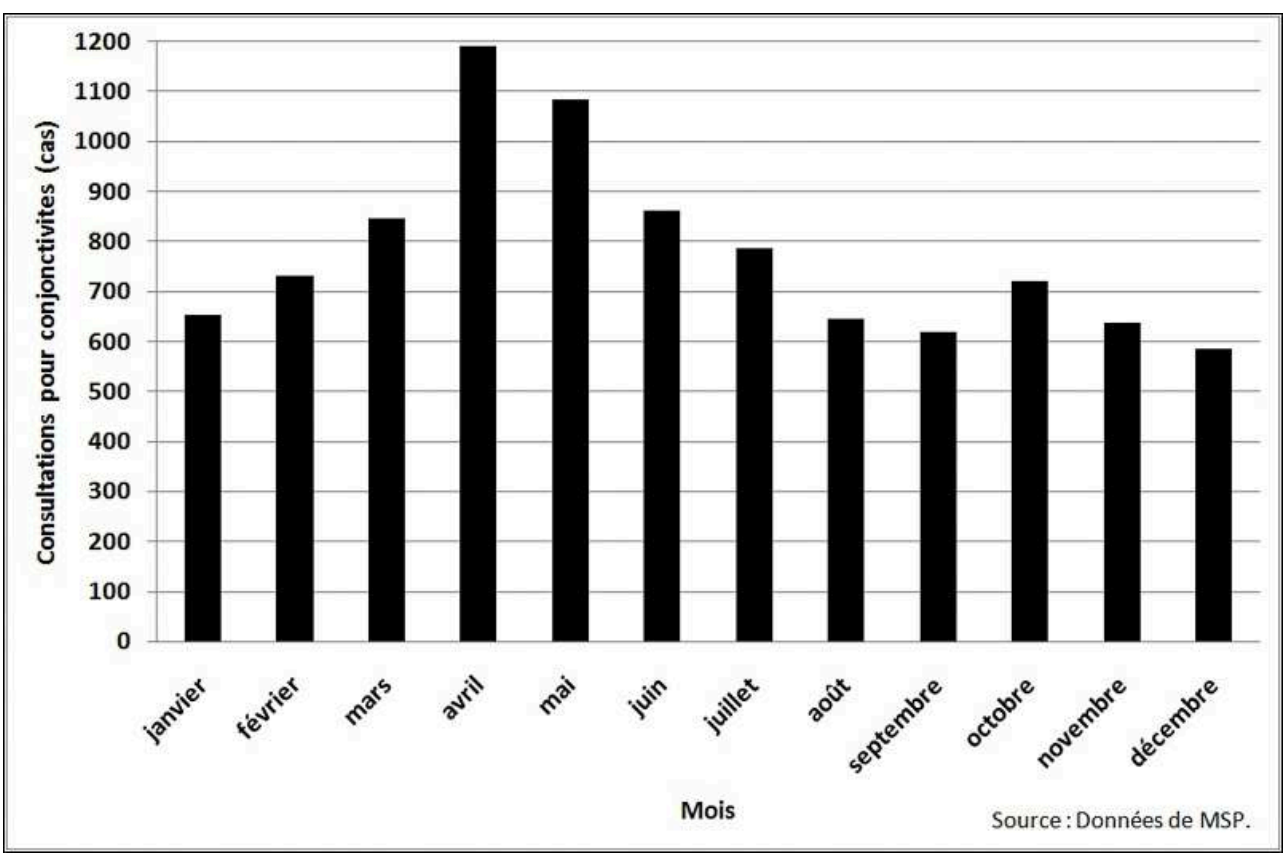

Sources : données MSP. Auteur : M. Jarraya.

\section{De bas niveaux thermiques favorables}

11 Nous avons retenu les jours qui ont enregistré un écart thermique négatif par rapport à la température moyenne mensuelle. À l'échelle hivernale, le nombre de ces jours est marqué par une variation inter-annuelle, puisqu'il varie de 28 jours en 2003 à 44 jours en 2009. En outre, l'écart thermique négatif moyen enregistré par rapport à la moyenne mensuelle varie de $-1,6^{\circ} \mathrm{C}$ en 2004 et 2011 à $-3^{\circ} \mathrm{C}$ en 2010 . L'analyse fait apparaître des contrastes inter-mensuels. Nous remarquons que les jours enregistrant l'écart de $-1^{\circ} \mathrm{C}$ sont plus fréquents. De surcroît, nous constatons que plus l'écart s'amplifie, plus le nombre de jours diminue. Par exemple, l'effectif des jours enregistrant l'écart de $-1^{\circ} \mathrm{C}$ est de 7 jours en janvier, alors qu'il est de 0,4 jours pour l'écart de $-5^{\circ} \mathrm{C}$ sur la période 2003-2015 (illustration 4). À l'échelle journalière, le temps est beaucoup plus frais, ce qui rend les conditions plus favorables à la propagation des agents pathogènes responsables des conjonctivites. Cela se répercute directement sur la morbidité enregistrée par les CSB à Sfax. 
Illustration 4 - Variation mensuelle du nombre de jours frais selon l'écart thermique négatif en hiver sur la période 2003-2015

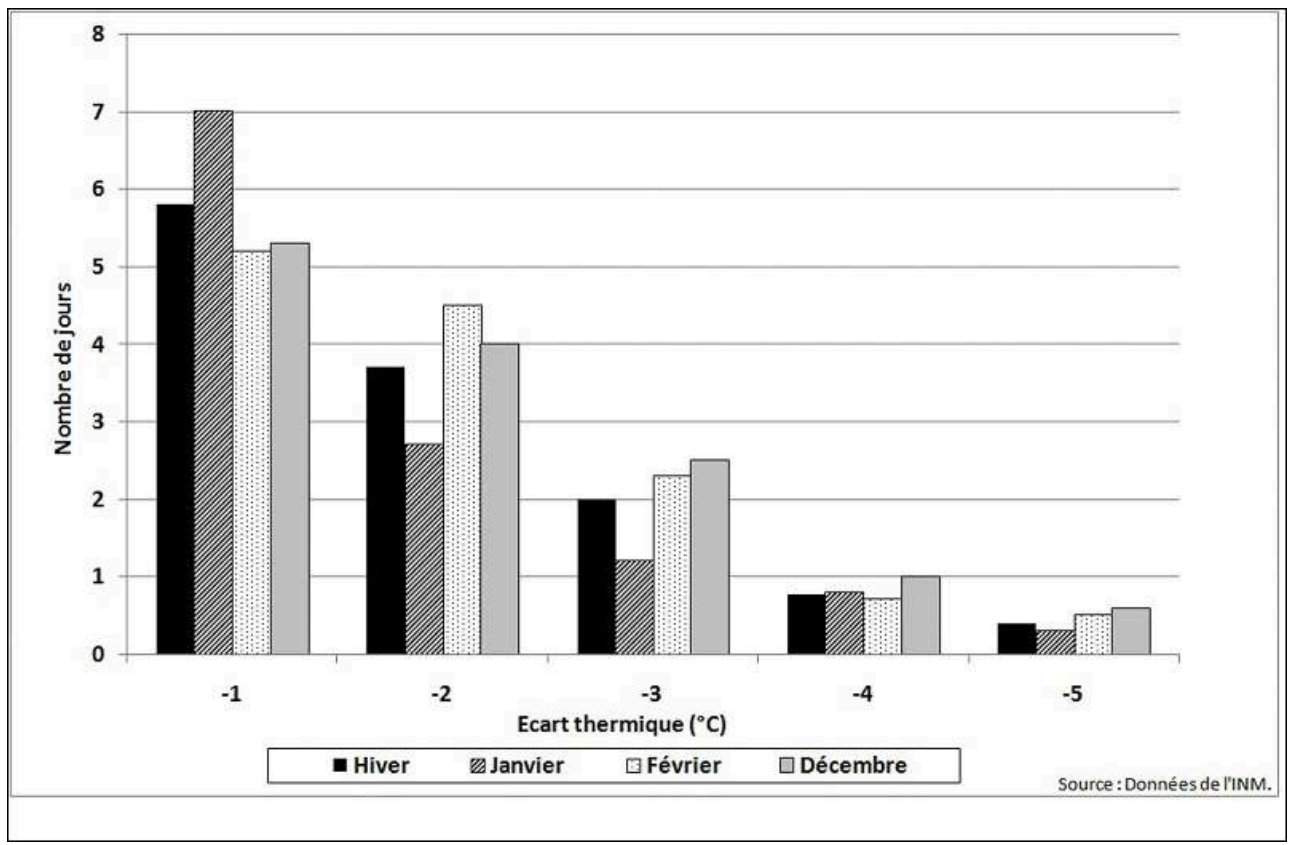

Sources : données INM. Auteur : M. Jarraya.

\section{Quels impacts sur la morbidité liée aux conjonctivites?}

À l'échelle hivernale, la consultation moyenne journalière pour conjonctivites croît en concordance avec l'accentuation de l'écart négatif et donc de la fraîcheur à Sfax. En effet, l'écart de $-1^{\circ} \mathrm{C}$ est associé à une consultation moyenne de 24 cas, alors que l'accentuation de cet écart qui atteint $-5^{\circ} \mathrm{C}$, s'accompagne d'une consultation moyenne de 41 cas (illustration 5), soit un accroissement de 70,8\%. À l'échelle mensuelle, l'accentuation de l'écart thermique négatif de -1 à $-5^{\circ} \mathrm{C}$ en janvier s'accompagne d'un accroissement de la morbidité liée aux conjonctivites respectivement de 25 cas à 40 cas (id.). 
Illustration 5 - Variation des consultations moyennes pour conjonctivites correspondantes aux écarts thermiques négatifs par mois en hiver sur la période 2003-2015

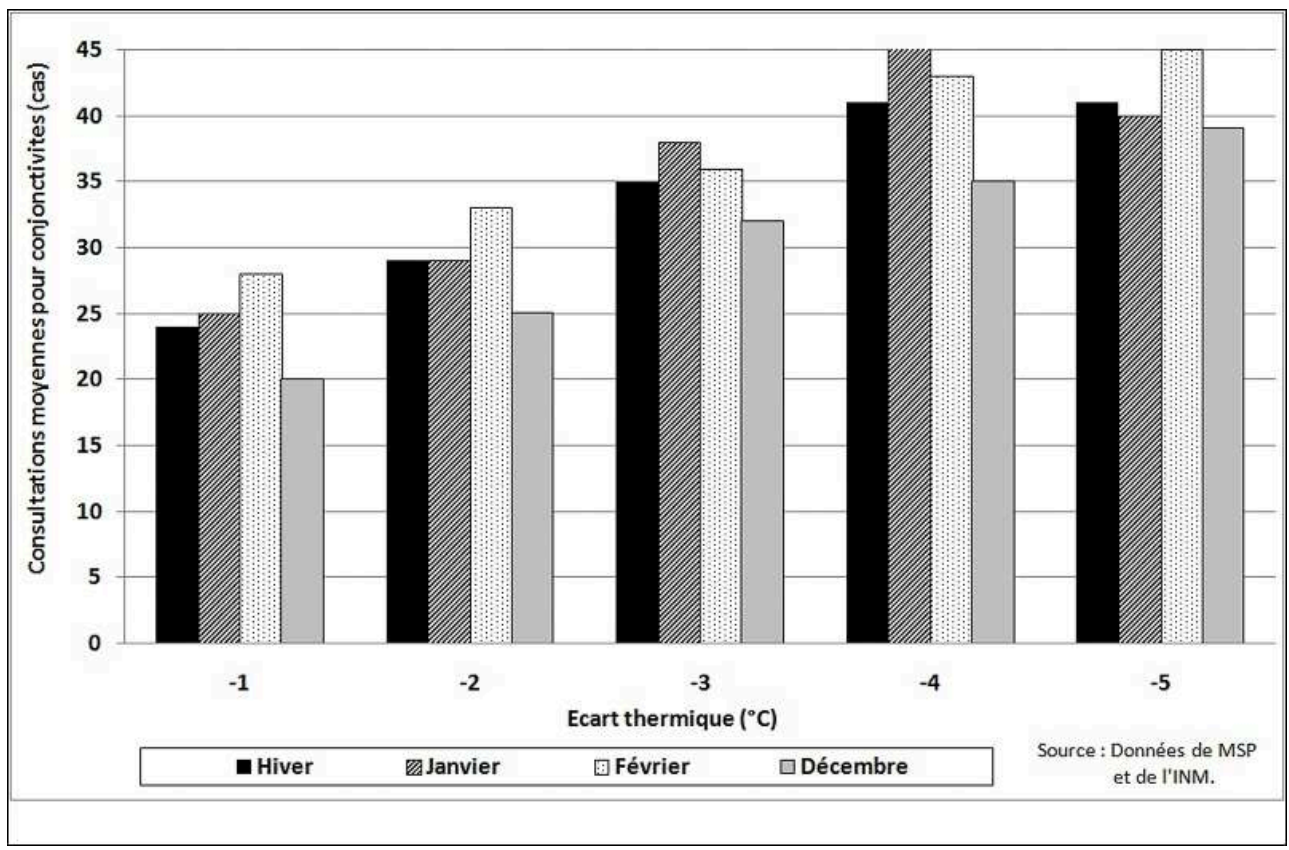

Sources : données MSP et INM. Auteur : M. Jarraya.

\section{Aspects météopathologiques liés aux situations atmosphériques hivernales à Sfax}

Le calcul de l'écart thermique journalier par rapport à la température moyenne mensuelle montre que $45 \%$ des jours en janvier (14 jours) enregistrent un écart thermique variant de $-1^{\circ} \mathrm{C}$ à $-3^{\circ} \mathrm{C}$ en janvier 2012. Nous avons associé par la suite l'écart thermique enregistré dans une journée donné (J) à la consultation pour conjonctivites enregistrée au lendemain $(\mathrm{J}+1)$. Cela est expliqué par le fait que toute situation climatique donnée est susceptible de produire des répercussions postérieures sur la morbidité. Enfin, les deux analyses séquentielles dégagent des aspects météopathologiques. Il ressort que la consultation augmente notablement en concordance avec le maintien de la fraîcheur. Par exemple, l'augmentation de l'écart thermique de $-1^{\circ} \mathrm{C}$ le 10 janvier à $-3^{\circ} \mathrm{C}$ le 11 janvier va de pair avec l'accroissement des consultations pour conjonctivites respectivement de 18 cas à 35 cas (illustration 6). 
Illustration 6 - Consultations pour conjonctivites correspondantes aux jours enregistrant des écarts thermiques négatifs avec la moyenne mensuelle en janvier 2012

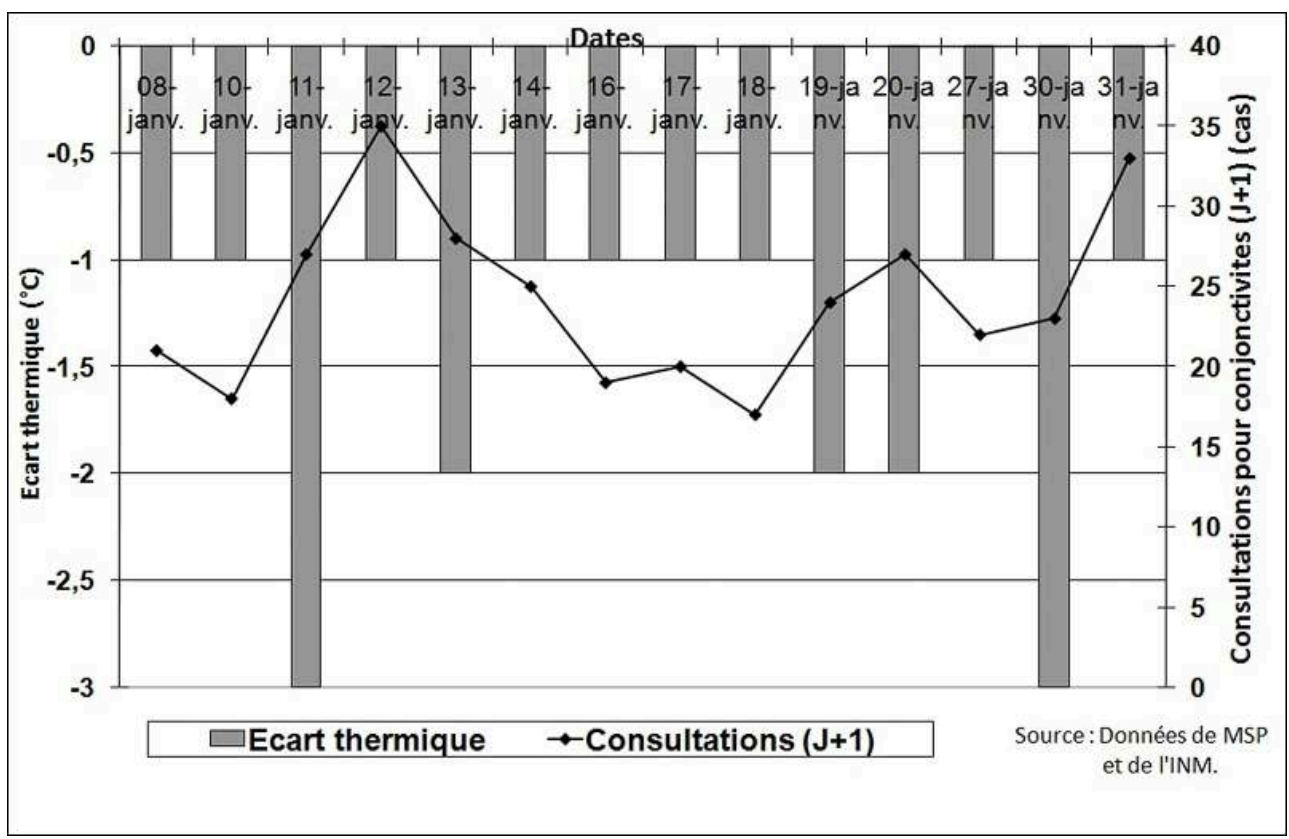

Sources : données MSP et INM. Auteur : M. Jarraya.

Afin de comprendre l'accentuation de la morbidité liée aux conjonctivites, nous analysons l'évolution la situation météorologique durant laquelle l'écart négatif maximal peut être enregistré deux fois. De ce fait, nous avons ainsi choisi deux séquences s'étalant sur deux jours (les 10 et 11 janvier 2012 et les 29 et 30 janvier 2012). De plus, nous avons analysé la température, l'humidité relative, la direction et la vitesse du vent qui déterminent l'ambiance thermique influençant la morbidité liée aux conjonctivites.

L'analyse de l'évolution de la situation météorologique depuis le 10 janvier permet de comprendre le niveau élevé de la morbidité enregistrée le 11 janvier (35 consultations). En effet, les directions $\mathrm{N}$, NW et WNW qui représentent $81,2 \%$ de l'effectif total des observations prédominent pendant la séquence du 10-11 janvier 2012 (illustration 7A). Les cartes synoptiques montrent la prise de relais d'une situation anticyclonique le 11 janvier après le passage d'une autre dépressionnaire caractérisée par un front froid le 10 janvier. Ce changement permet d'observer la direction de vent WNW qui souffle selon une vitesse moyenne de $1,8 \mathrm{~m} / \mathrm{s}$ le 11 janvier (illustrations $7 \mathrm{~B}$ et $7 \mathrm{C}$ ), ce qui n'a pas été le cas le 10 janvier. Cela est expliqué par l'installation des cellules de haute pression au Nord et à l'Ouest de la Tunisie (illustrations 7E et 7F). Il en résulte que l'air est devenu plus froid et sec. Outre l'amplification de l'écart thermique par rapport à la moyenne mensuelle (de $-1^{\circ} \mathrm{C}$ à $-3^{\circ} \mathrm{C}$ entre le 10 et 11 janvier), l'amplitude thermique journalière a également augmenté de $8^{\circ} \mathrm{C}$ à $11^{\circ} \mathrm{C}$ durant cette séquence. De plus, l'humidité relative journalière de l'air est peu élevée ( $60 \%$ en moyenne durant la séquence) (illustration 7D). Le passage d'une situation dépressionnaire à une autre anticyclonique a pour effet de modifier les propriétés de l'air dans la région de Sfax (NW ou le WNW après un parcours sur le continent). Cela signifie que l'air devient plus frais la nuit et moins humide le jour. Cette situation fraîche s'avère favorable à une activité virale importante pour infecter l'œil indépendamment ou conjointement avec la rhinopharyngite et la grippe, ce qui rehausse la morbidité liée aux conjonctivites du 
18 cas à 35 cas entre le 10 et 12 janvier 2012 (illustration 6). Selon nos entretiens avec les médecins traitant dans les CSB, la conjonctivite virale est contagieuse et causée par le même virus (l'adénovirus) trouvé également dans les narines et la gorge. Toutes les classes d'âge peuvent être affectées. Par un simple contact avec un sujet atteint ou un objet infecté par le virus, ce type de conjonctivite peut se transmettre très rapidement. Les ophtalmologues, avec qui nous nous sommes entretenus, ont confirmé que les symptômes peuvent durer de 5 à 10 jours et ont souligné que les quatre premiers jours sont les plus contagieux. À cause de cette forte contagiosité, tous les médecins questionnés parlent d'une "épidémie de conjonctivites ». Ils ont souligné également que ce sont les virus d'adénovirus et d'entérovirus qui survivent une longue période dans l'environnement extérieur et qui sont responsables des plus grandes épidémies de conjonctivites infectieuses hivernales.

Illustration7A - Rose des vents des 10 et 11 janvier 2012

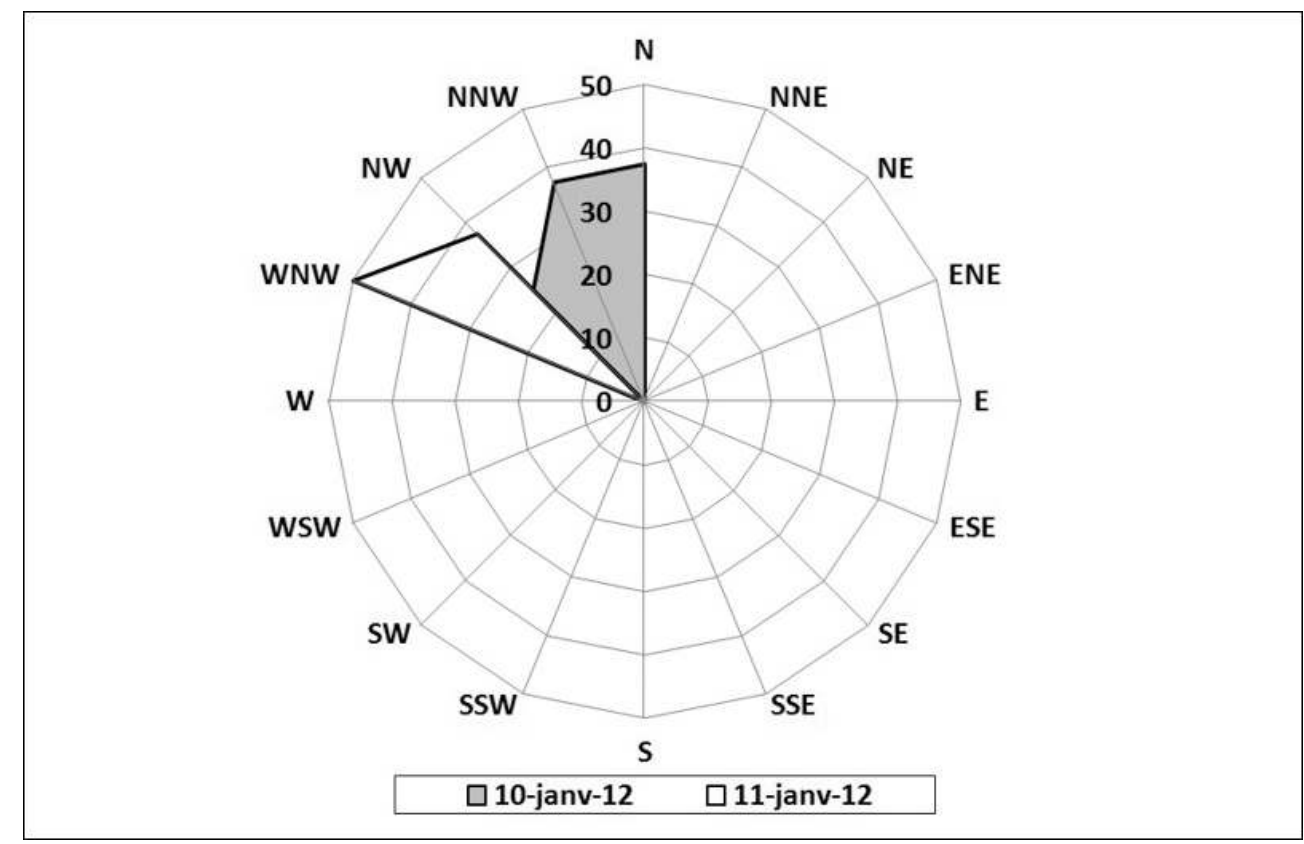

Source : Données INM. Auteur : M. Jarraya. 
Illustration 7B - Évolution des directions du vent entre les 10 et 11 janvier 2012

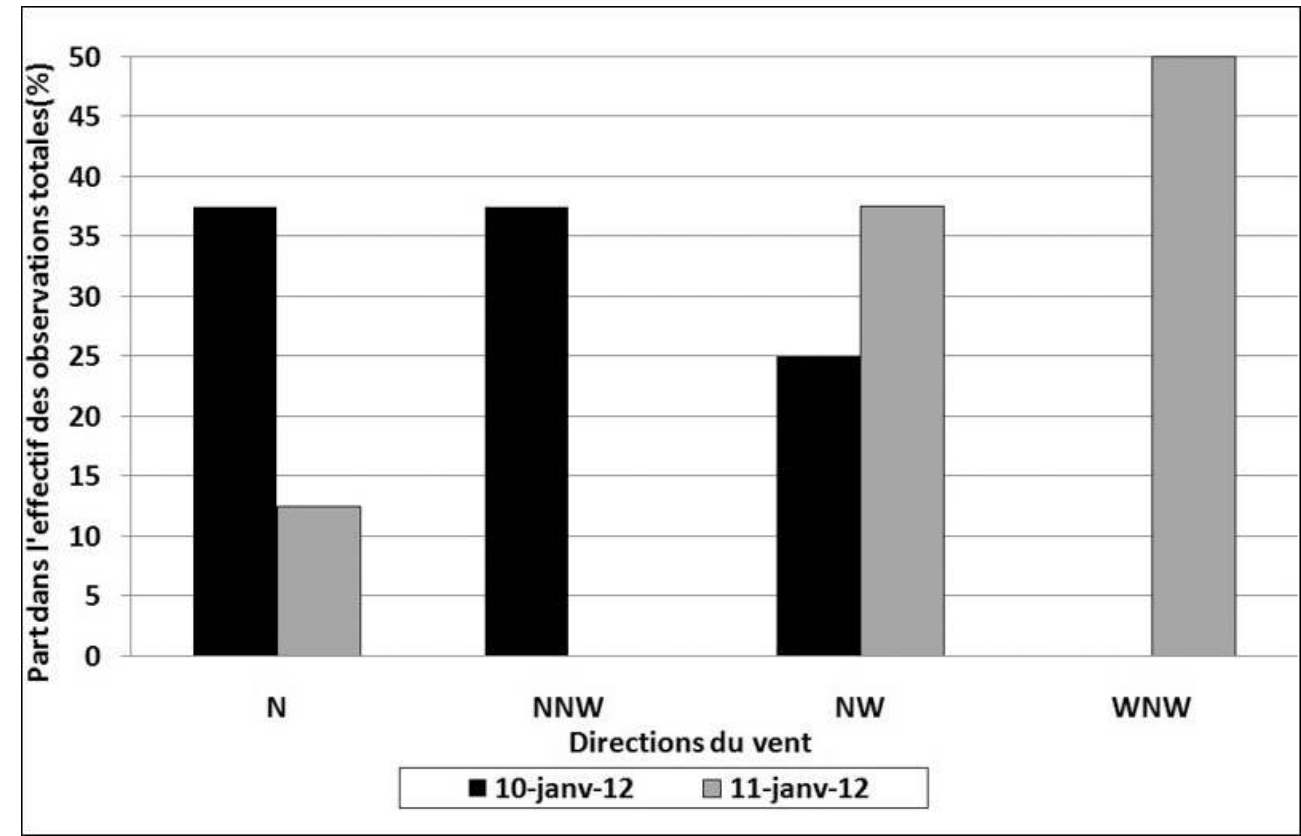

Source: Données INM. Auteur : M. Jarraya

Illustration 7C - Directions du vent et vitesse moyennes associées pendant la séquence 10-11 janvier 2012

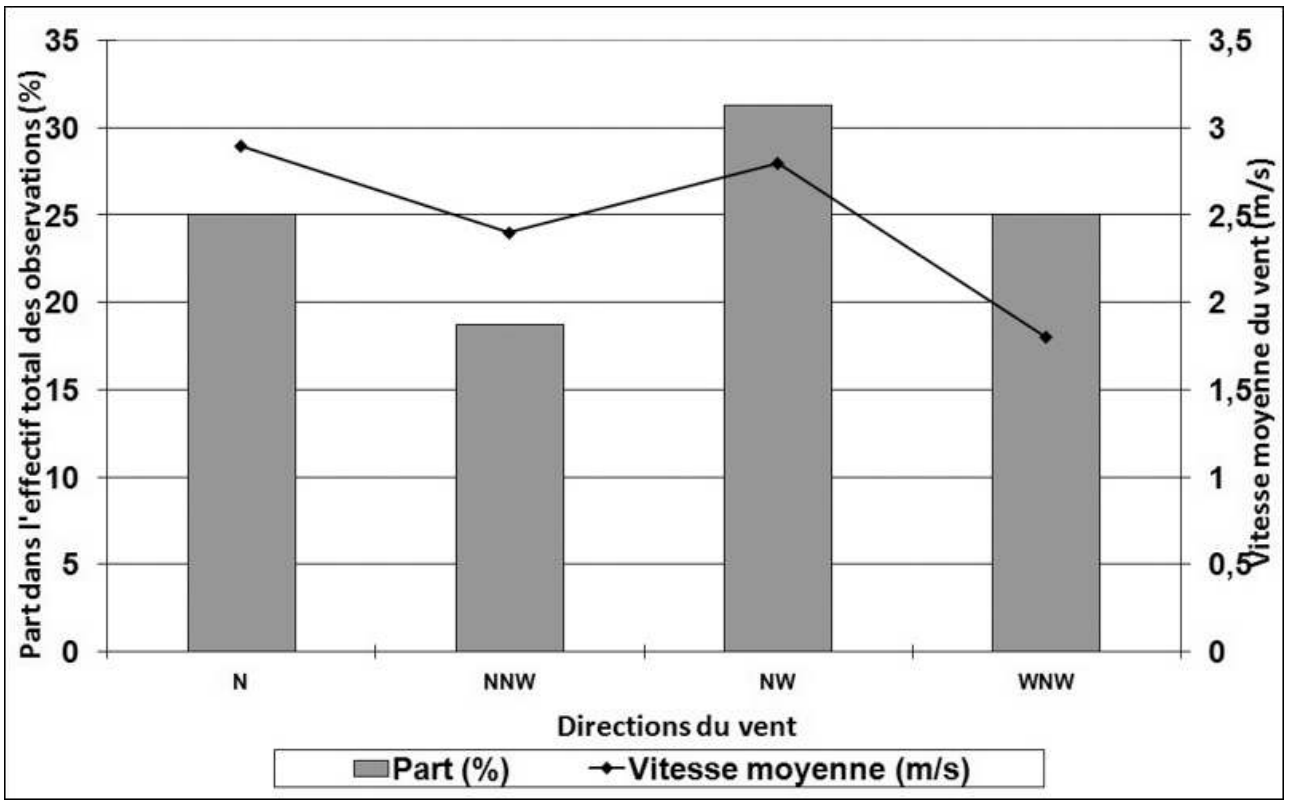

Source : Données INM. Auteur: M. Jarraya. 
Illustration 7D - Évolution de l'humidité relative entre les 10 et 11 janvier 2012

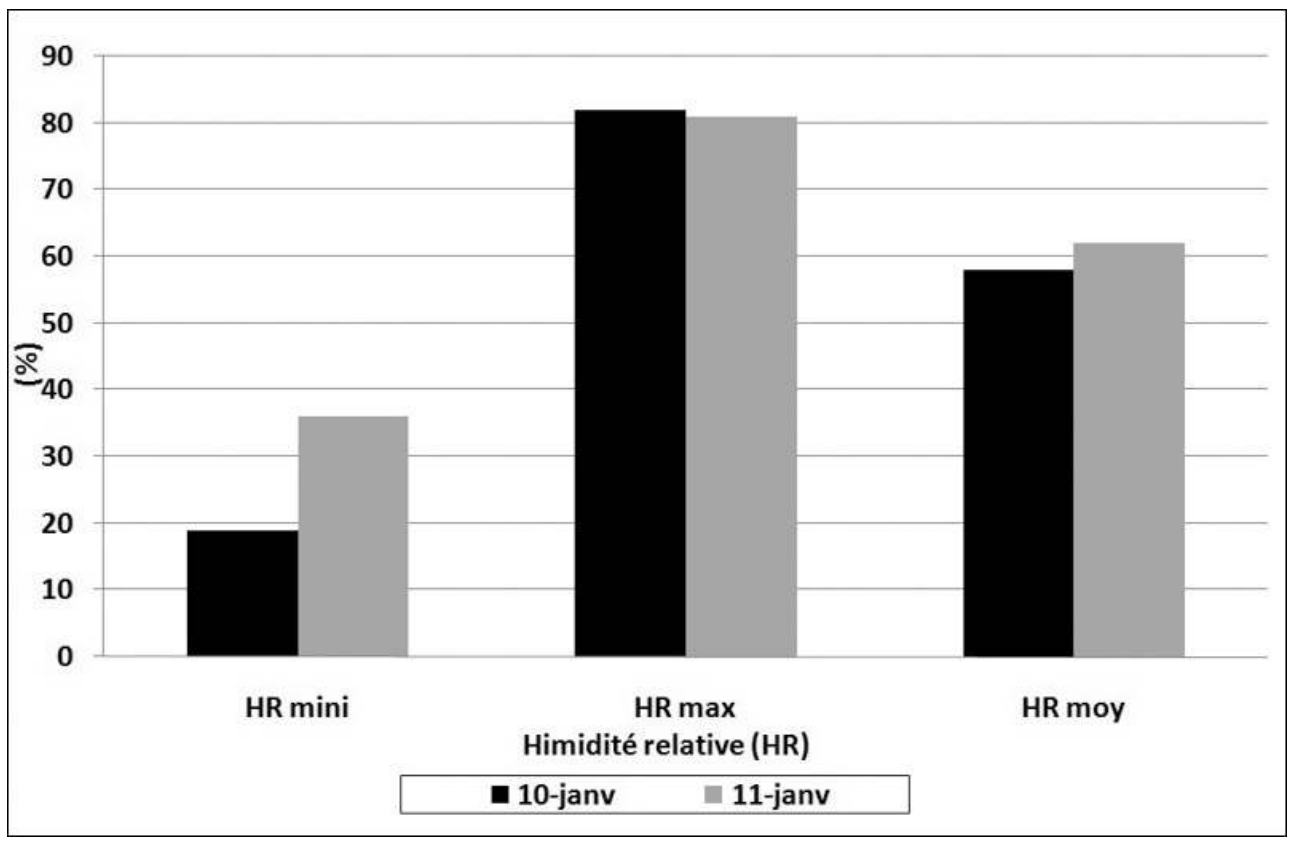

Source : Données de l'Institut National de la Météorologie. Auteur : M. Jarraya.

Illustration 7E - Situation en surface le 10 janvier 2012 à $00 \mathrm{~h}$ TU

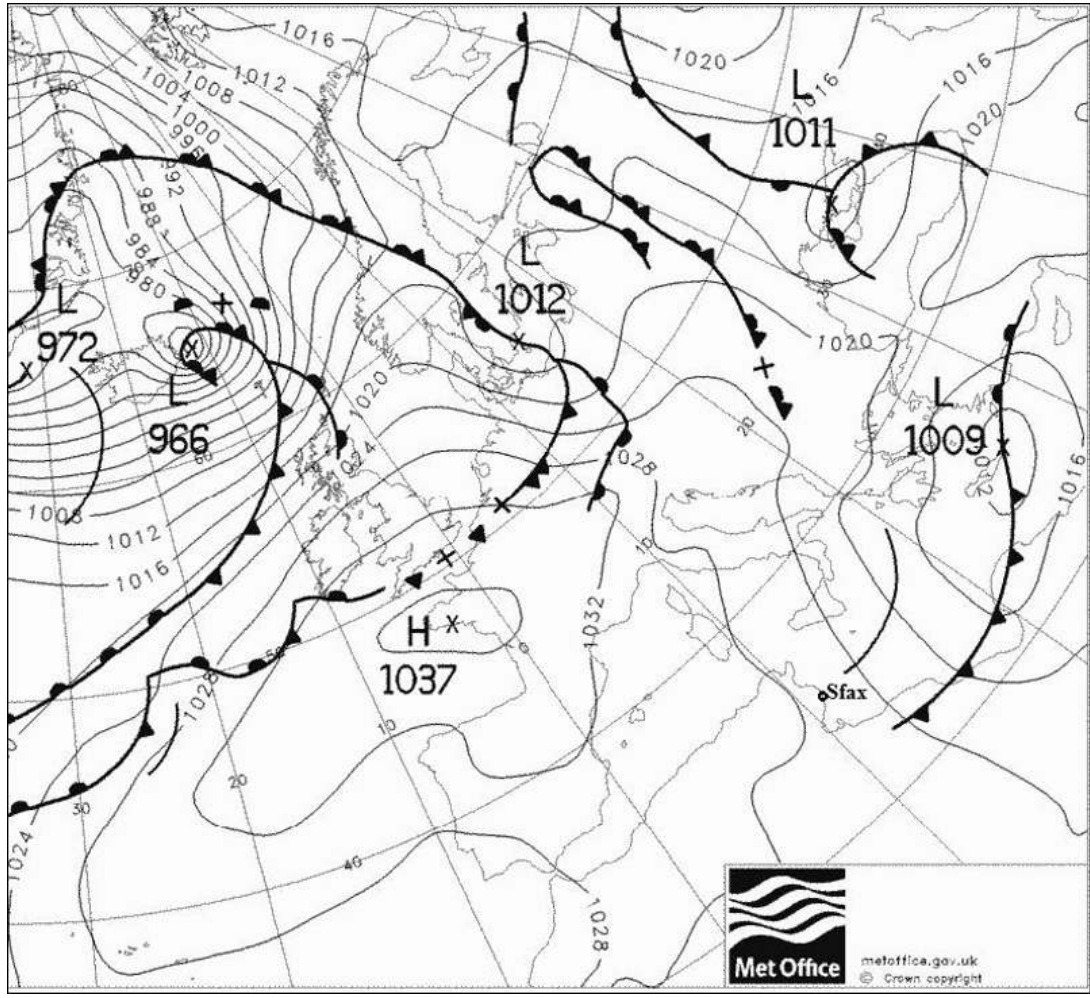

Source : www. metoffice.com. Auteur : M. Jarraya. 
Illustration 7F - Situation en surface le 11 janvier 2012 à $00 \mathrm{~h}$ TU

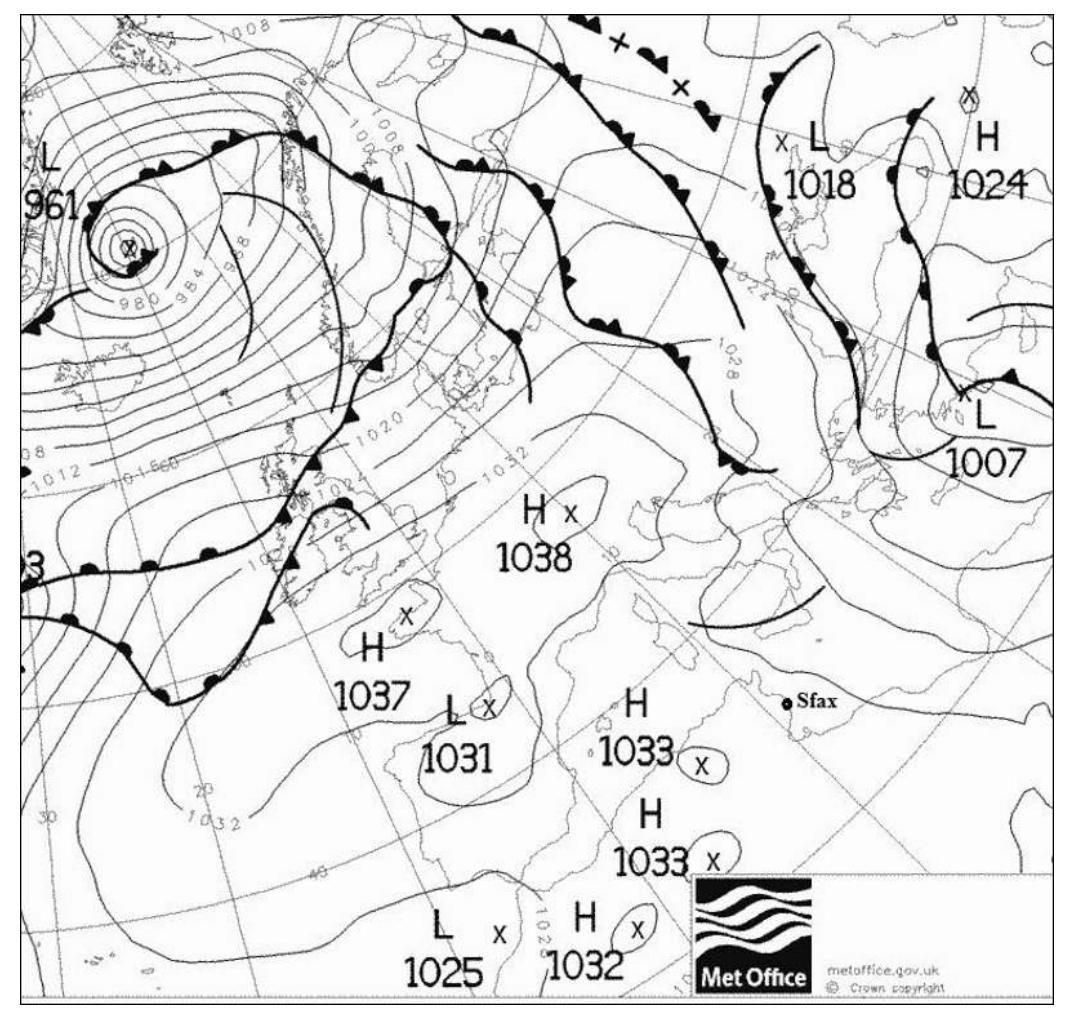

Source : www. metoffice.com. Auteur : M. Jarraya.

La deuxième séquence du 29-30 janvier 2012 se caractérise par la prédominance d'une situation dépressionnaire. Le contexte aérologique est marqué par la prédominance des directions $\mathrm{N}$ et NNW qui représentent $68,7 \%$ des observations totales (illustration $8 \mathrm{~A}$ ). Les cartes synoptiques montrent l'effet de deux cellules cycloniques qui se localisent au Nord et au Sud-Est de la Tunisie et dont la perturbation du 29 janvier 2012 en constitue le passage le plus important (illustration 8E). Le 30 janvier, la totalité du pays se situe au cœur de cette perturbation (illustration $8 \mathrm{~F}$ ), laquelle est à l'origine de l'advection du vent de direction $\mathrm{W}$ selon une vitesse de $3,6 \mathrm{~m} / \mathrm{s}$ (illustrations $8 \mathrm{~B}$ et $\mathrm{C}$ ). En outre, l'illustration $8 \mathrm{~B}$ montre que les directions du vent $\mathrm{NW}$, WNW et $\mathrm{W}$ sont enregistrées seulement le 30 janvier 2012. 
Illustration 8A - Rose des vents des 29 et 30 janvier 2012

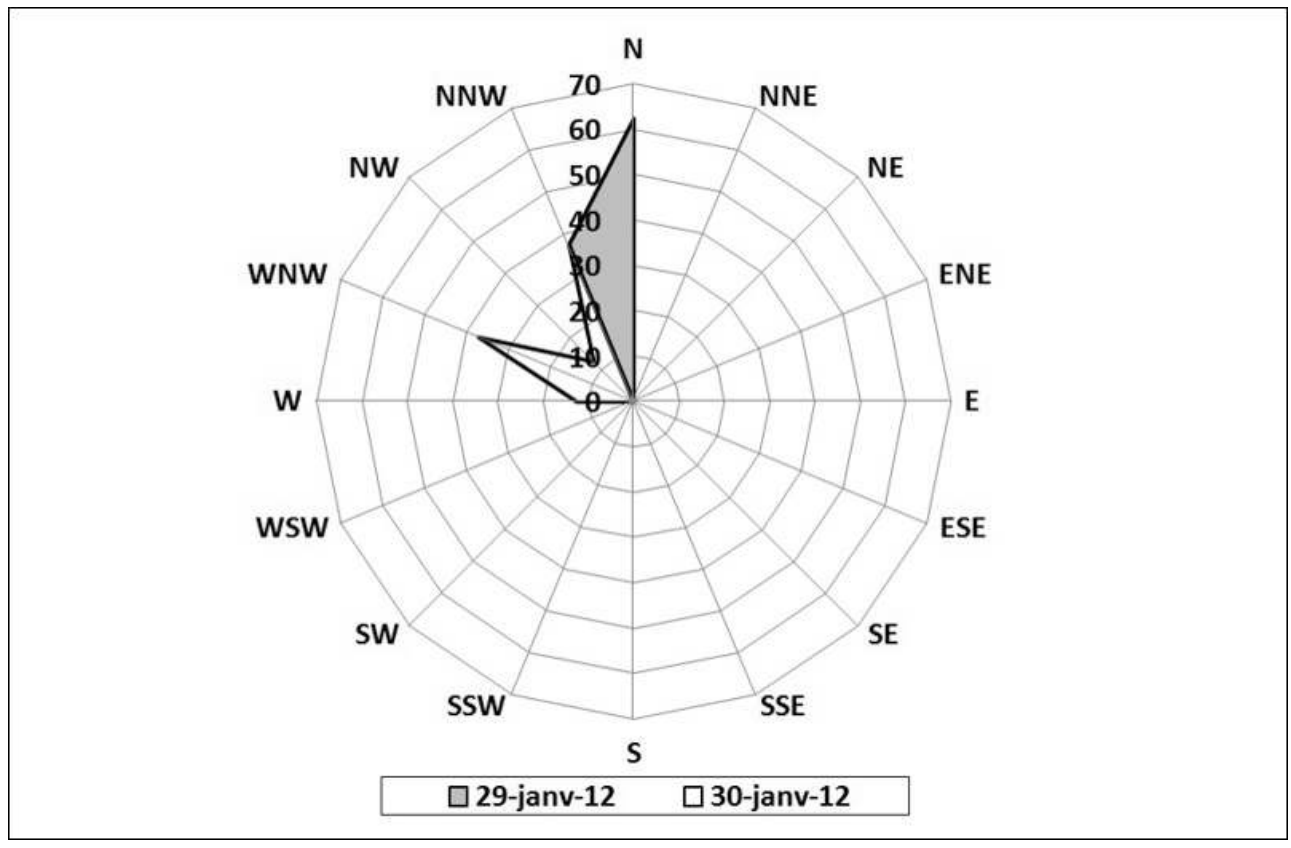

Source: Données INM. Auteur : M. Jarraya.

Illustration 8B - Évolution des directions du vent entre les 29 et 30 janvier 2012

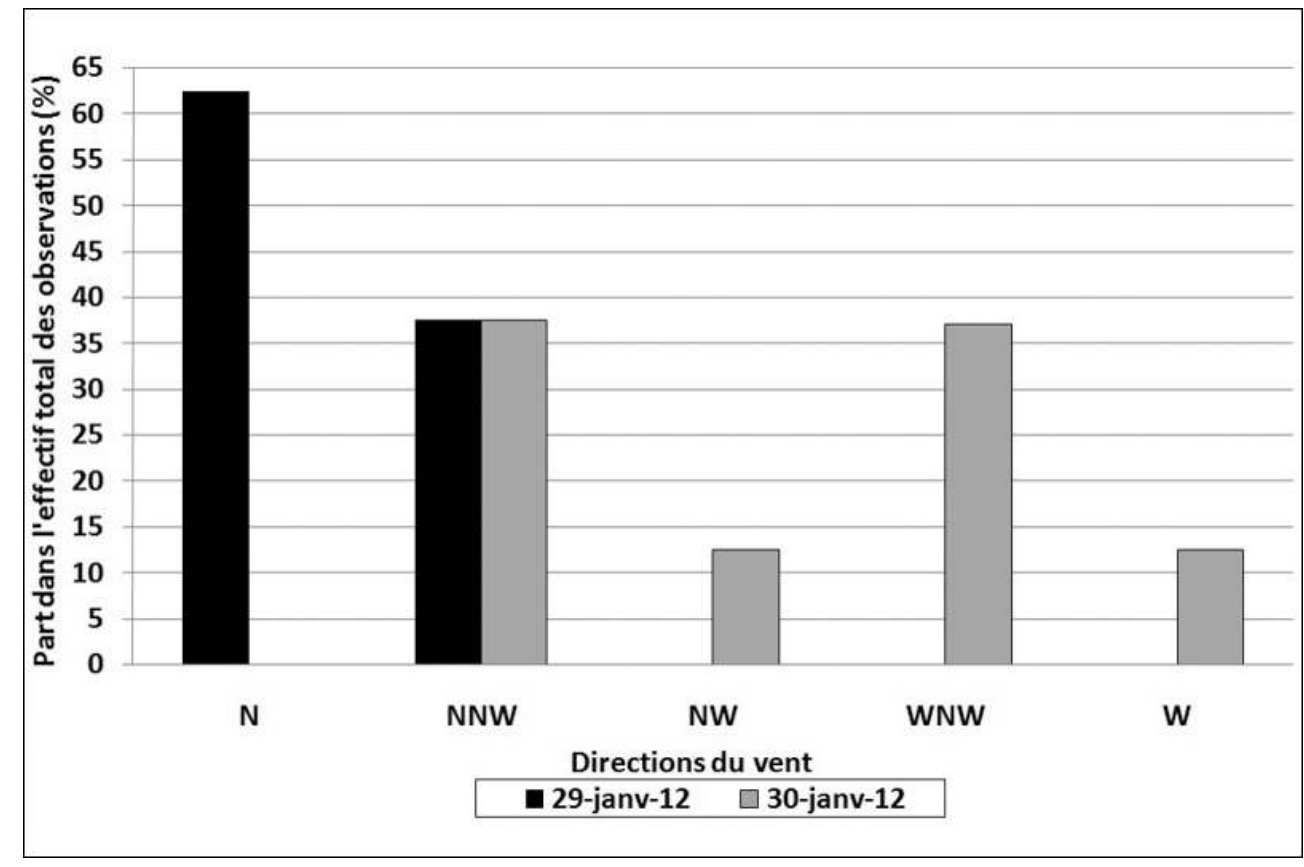

Source : Données INM. Auteur : M. Jarraya. 
Illustration 8C - Directions du vent et vitesse moyennes associées pendant la séquence 29-30 janvier 2012

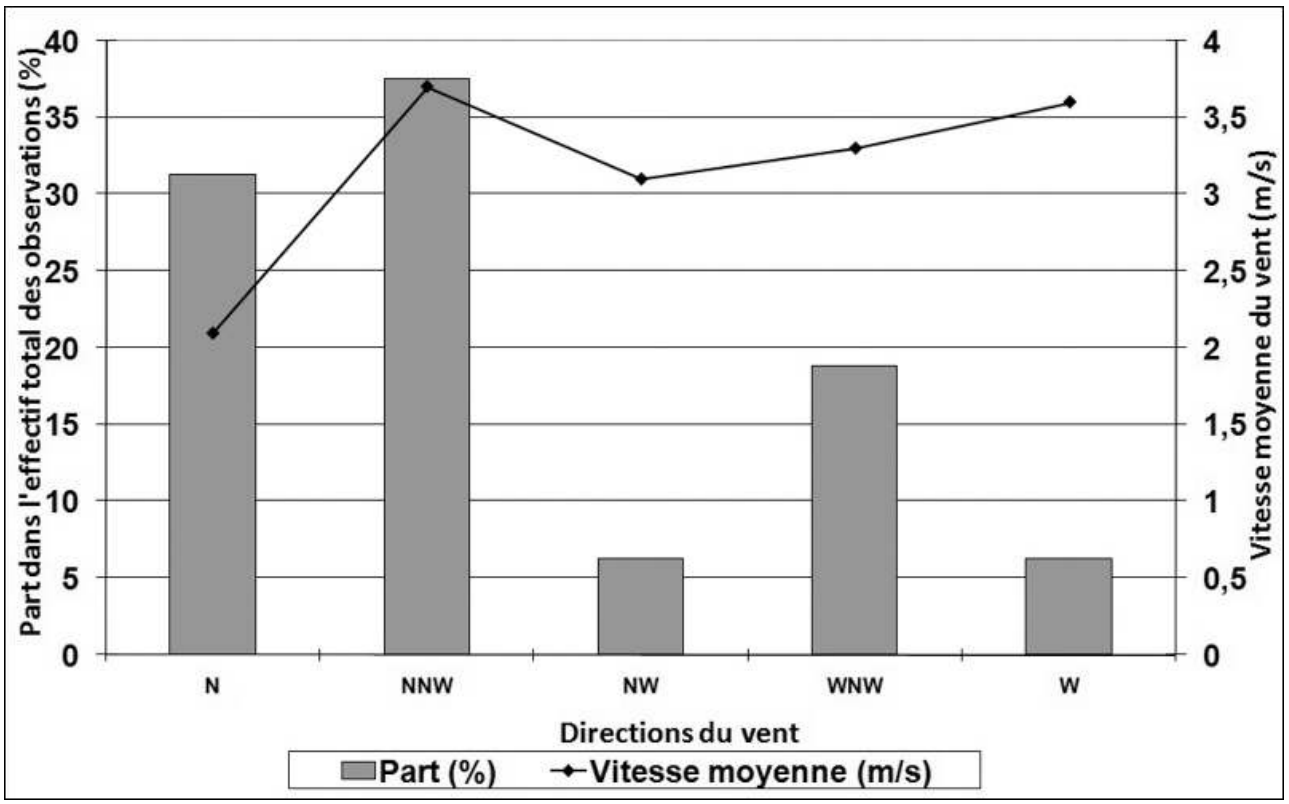

Source: Données INM. Auteur: M. Jarraya.

Illustration 8D - Évolution de l'humidité relative entre les 29 et 30 janvier 2012

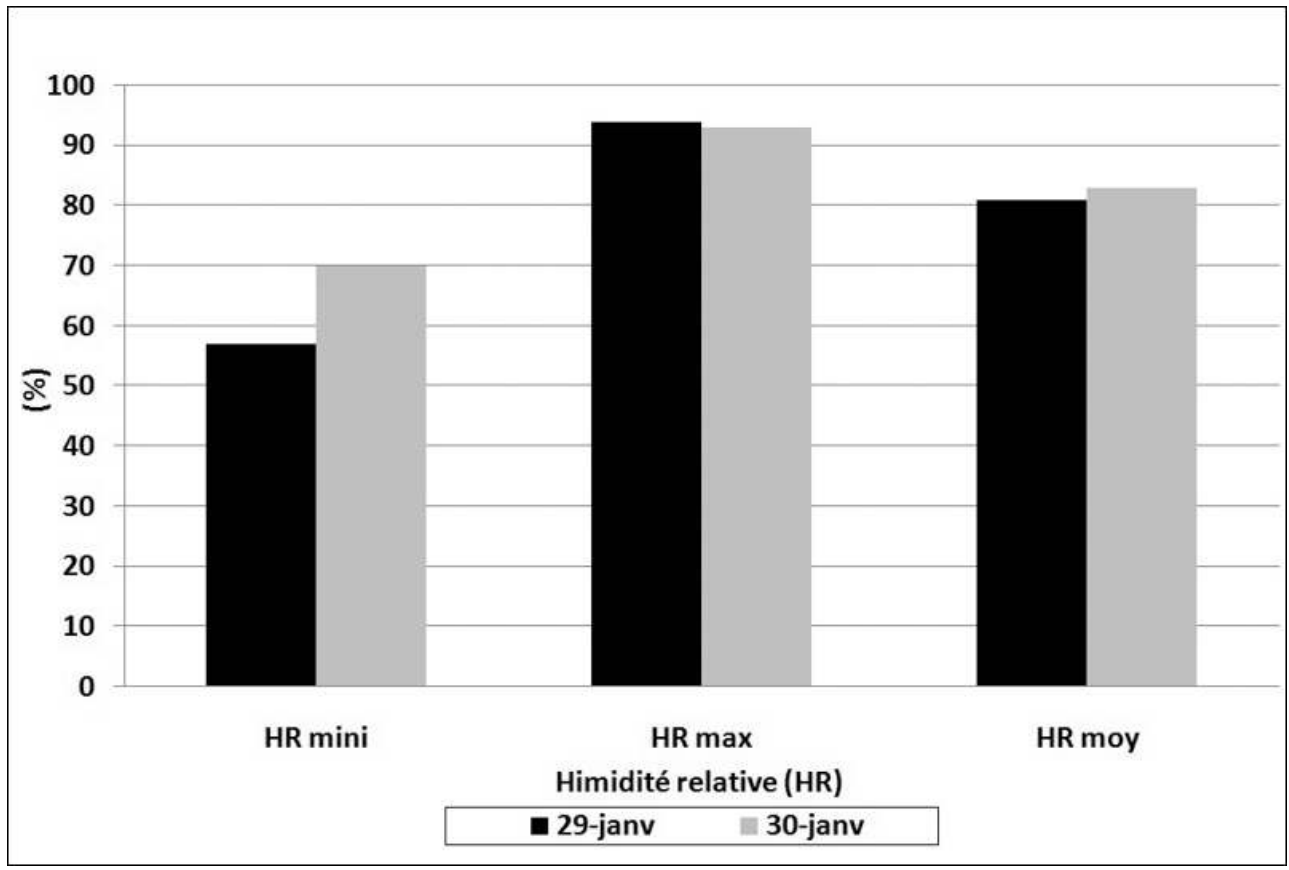

Source : Données INM. Auteur : M. Jarraya. 
Illustration $8 \mathrm{E}$ - Situation en surface le 29 janvier 2012 à $00 \mathrm{~h}$ TU

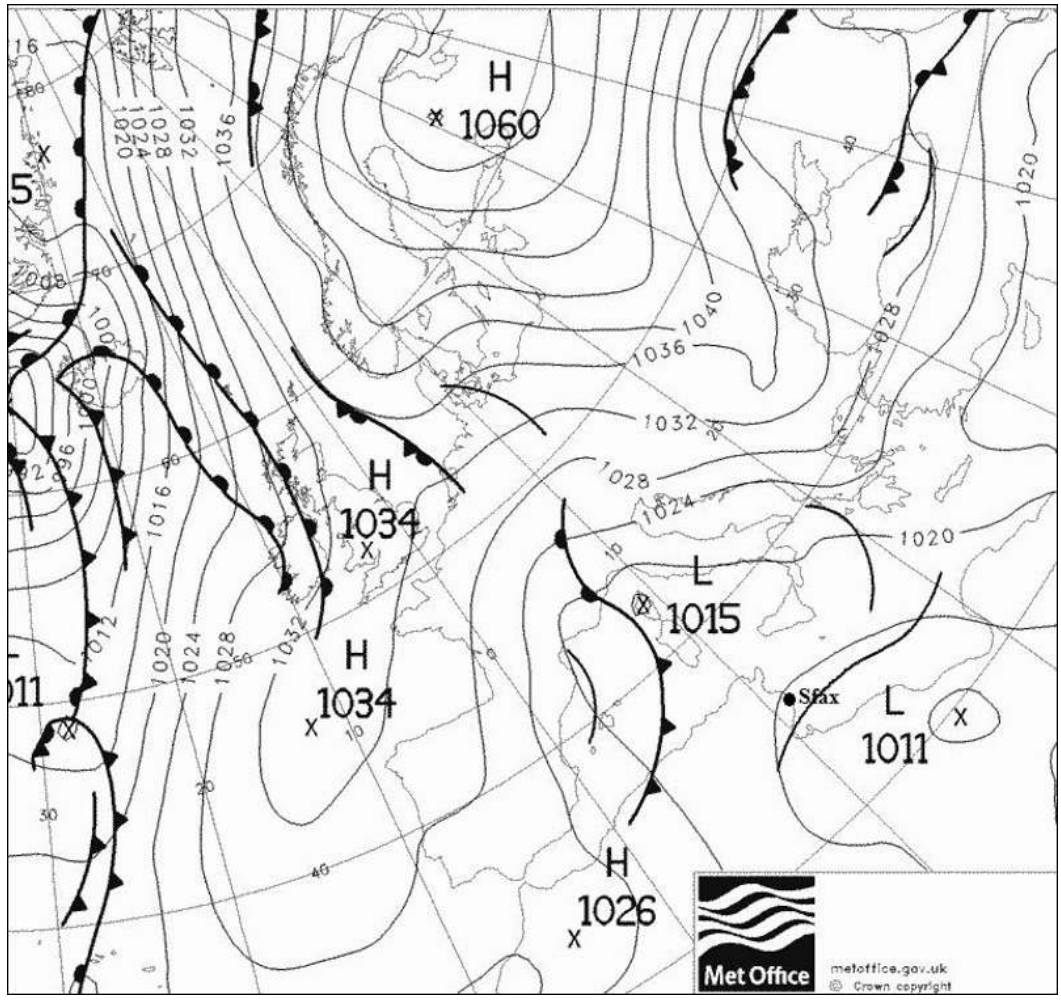

Source : www.metoffice.com. Auteur : M. Jarraya

Illustration $8 \mathrm{~F}$ - Situation en surface le 30 janvier 2012 à $00 \mathrm{~h}$ TU

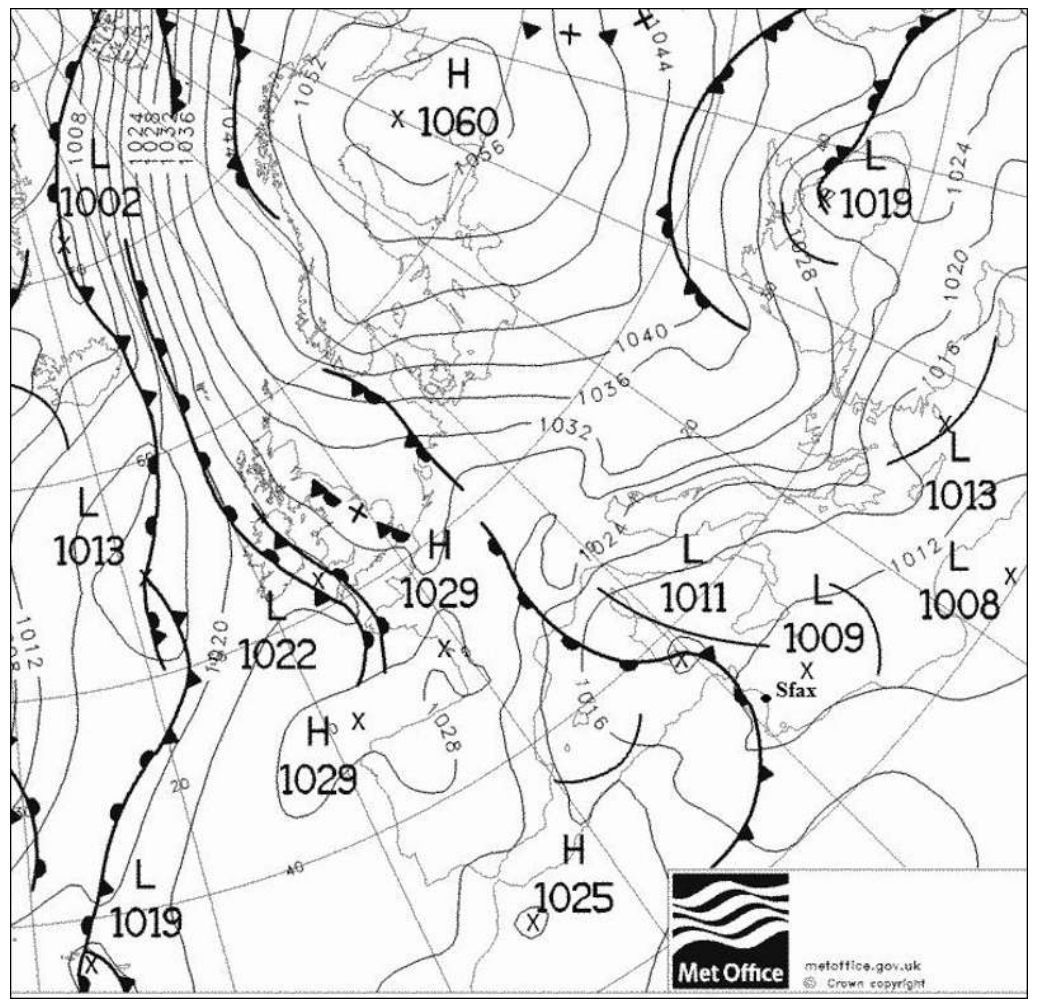

Source : www.metoffice.com. Auteur : M. Jarraya 
17 En comparaison avec la séquence précédente, les effets sur la température et sur l'humidité de l'air sont plus modérés. Bien qu'un écart thermique se creuse davantage $\left(-3^{\circ} \mathrm{C}\right.$ le 30 janvier), nous notons que l'amplitude thermique journalière reste quasistable entre le 29 janvier $\left(4^{\circ} \mathrm{C}\right)$ et le 30 janvier $\left(5^{\circ} \mathrm{C}\right)$. De plus, cette séquence se caractérise par une humidité moyenne relativement élevée de $82 \%$ et en particulier une humidité minimale de $70 \%$ enregistrée au cours de la journée du 30 janvier (illustration 8D). Un tel contexte cyclonique explique une ambiance fraîche et humide observée le 30 janvier 2012 qui s'avère propice à un accroissement des consultations pour conjonctivites de 23 cas à 33 cas entre le 30 et 31 janvier 2012. Si nous avons attribué, dans la précédente séquence fraîche (10-11 janvier 2012), la hausse de cette morbidité à un contexte thermique frais et sec, la fraîcheur et l'humidité de l'air caractérisant cette séquence peuvent influencer autrement les conjonctivites.

Nos entretiens avec les médecins des CSB, les ophtalmologues et les pneumologuesallergologues révèlent que cet effet indirect découle de l'influence d'un air très humide sur la fréquence de deux types de conjonctivites. Le premier type est bactérien qui est souvent associé à une otite moyenne qui survient après 3 ou 4 jours de l'affection. L'humidité de l'air élevée en hiver favorise les infections d'origine bactérienne comme les otites et les angines (Jarraya, 2009). Certaines bactéries responsables des conjonctivites comme l'Haemophilus influenzae non typable et le Moraxella catarrhalis, etc. deviennent plus actives sous un air froid et humide à l'extérieur, mais leur effet s'accentue dans les milieux fermés et mal ventilés. Le deuxième type est d'origine allergique. Les médecins interrogés ont confirmé que l'humidité croissante de l'air dans les maisons ou les lieux de travail peut aboutir au développement des moisissures et des acariens (Jarraya, 2018b). Ceux-ci produisent des toxines et des spores contribuant au déclenchement des allergies et des irritations respiratoires (Abouda et al., 2014). De plus, les résidus des acariens disposent des allergènes pouvant réactiver des rhinites allergiques, voire de l'asthme. La conjonctivite constitue ici l'un des symptômes de la rhinite allergique associé à l'écoulement nasal et à la toux.

Lors de la réalisation de notre enquête sur le contexte socio-environnemental de l'asthme en avril 2015, les patients ont confirmé le rapport intime qui existe entre les conjonctivites, les conditions d'habitat et la co-morbidité. En effet, les malades ont signalé qu'en hiver des signes allergiques se réactivent souvent sous l'effet de l'humidité de l'air froid accentuée par de mauvaises conditions d'habitat (Jarraya, 201bB). La conjonctivite est intimement liée à l'asthme, elle se manifeste le plus souvent en tant que symptôme d'une rhinite allergique.

20 Les deux séquences étudiées ont abouti à l'instauration de deux ambiances thermiquement fraîches mais différentes au niveau hygrométrique. Deux types de situations atmosphériques hivernales différentes ayant influencé différemment la morbidité liée aux conjonctivites indépendamment ou conjointement avec d'autres affections infectieuse ou allergique.

\section{... À une « bouffée » printanière}

21 Nous qualifions les niveaux élevés de morbidité liée aux conjonctivites de "bouffée ", pour exprimer sa recrudescence printanière notable à 1192 cas en avril (illustration 3). Cette morbidité est plus élevée que celui observé en hiver, ce qui nous amène à étudier l'évolution du contexte climatique qui tend à l'adoucissement thermique, afin 
d'avancer quelques éléments d'explication du paysage épidémiologique instauré au printemps.

\section{La tendance à l'adoucissement thermique}

Nous avons retenu les jours enregistrant un écart thermique positif par rapport à la température moyenne mensuelle. À l'échelle de la saison printanière, ce nombre moyen est de l'ordre de 38 jours sur la période 2003-2015. Nous remarquons une diminution de l'effectif des jours allant de pair avec l'accentuation de l'écart thermique positif au printemps, de 4,5 jours enregistrant un écart de $1^{\circ} \mathrm{C}$ à de 0,7 jours enregistrant un écart de $6^{\circ} \mathrm{C}$ (illustration 9). À l'échelle mensuelle, les jours enregistrant des écarts de $2^{\circ} \mathrm{C}$ et $3^{\circ} \mathrm{C}$ sont les plus fréquents avec des moyennes respectives de 4,7 et 3 jours en mars. Par ailleurs, les jours enregistrant un écart de $1^{\circ} \mathrm{C}$ prédominent en avril (5,4 jours) et mai (6,2 jours) sur la période 2003-2015 (illustration 9).

Illustration 9 - Variation mensuelle du nombre de jours doux selon l'écart thermique positif au printemps sur la période 2003-2015

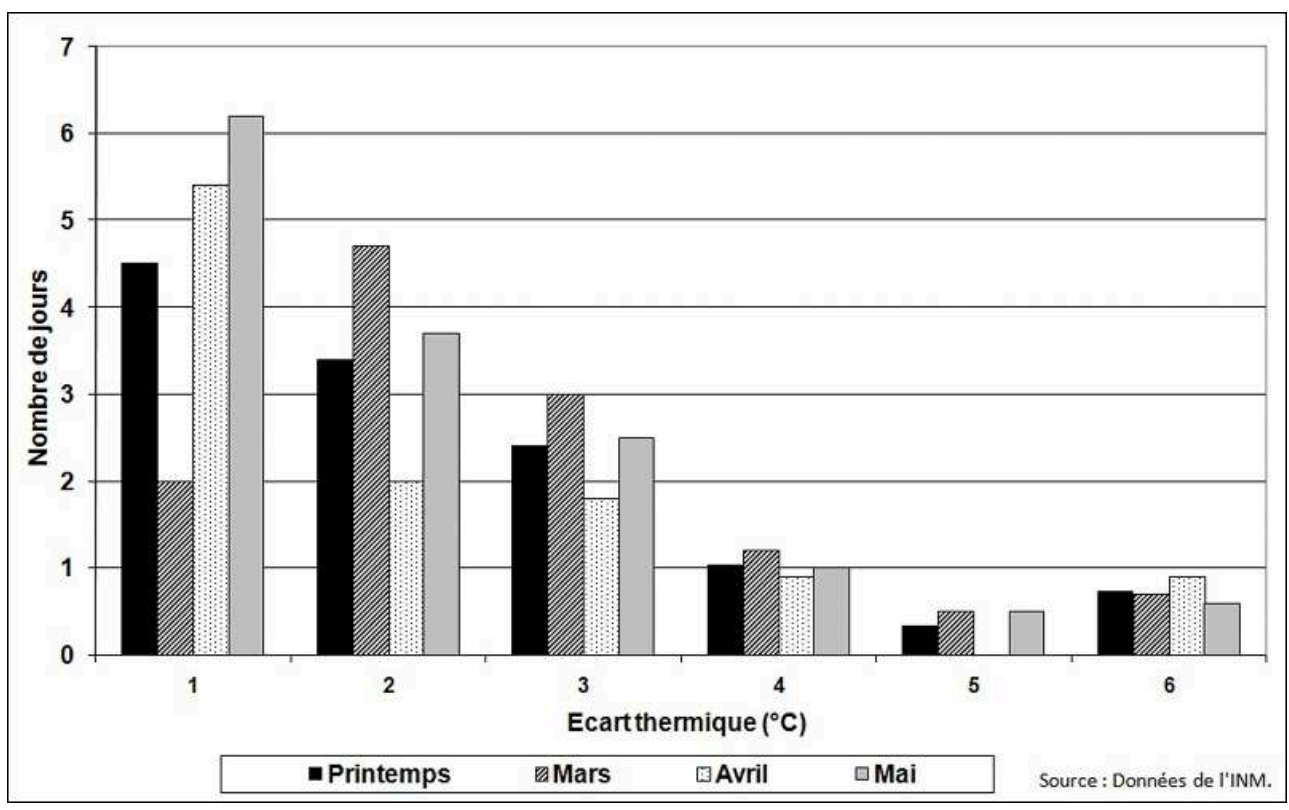

Source : Données INM. Auteur : M. Jarraya.

Nous avons opté pour le maintien de l'écart thermique positif comme un indicateur de l'adoucissement thermique à Sfax offrant éventuellement les conditions favorables à la recrudescence de la morbidité liée aux conjonctivites.

\section{Une morbidité associée élevée}

Le calcul des consultations moyennes pour conjonctivites correspondant aux jours doux reflète une relative augmentation. Une augmentation que la nous pouvons attribuer à la tendance de l'adoucissement thermique exprimé par cet écart positif. À l'échelle de la saison printanière, la consultation moyenne journalière augmente nettement (de 26 cas à 41 cas) au fur et à mesure que l'écart thermique se creuse de $1^{\circ} \mathrm{C}$ à $4^{\circ} \mathrm{C}$ sur la période 2003-2015 (illustration 10). 
Illustration 10 - Consultations moyennes pour conjonctivites correspondantes aux écarts thermiques positifs par mois au printemps sur la période 2003-2015

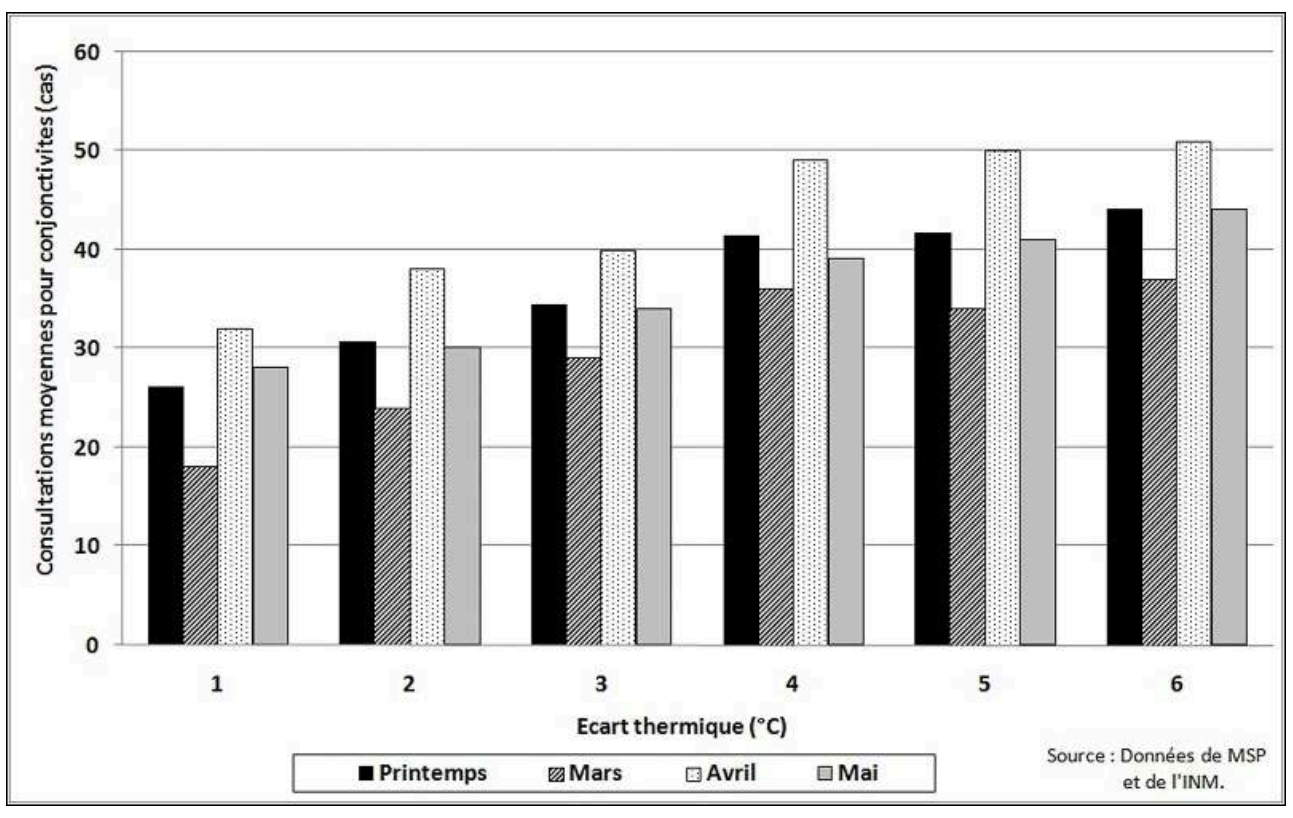

Source : Données MSP et INM. Auteur : M. Jarraya.

En outre, le rythme d'accroissement des consultations décélère au-delà d'un écart thermique de $4^{\circ} \mathrm{C}$ pour atteindre 44 cas pour les jours enregistrant un écart thermique de $6^{\circ} \mathrm{C}$ (illustration 10). Cependant, le rythme est variable au niveau de « la réponse » de la morbidité liée aux conjonctivites puisque l'augmentation est nette au niveau de la consultation moyenne (38 cas) correspondant à l'intervalle [3-4 $4^{\circ} \mathrm{C}$, par opposition à celle qui correspond à l'intervalle $\left[1-2^{\circ} \mathrm{C}\right]:$ (29 cas) (illsutration 11). Le taux d'augmentation est donc de $31 \%$. À l'échelle mensuelle, nous remarquons l'accroissement de cette morbidité qui va de pair avec l'amplification de l'écart thermique positif. 
Illustration 11 - Consultations moyennes pour conjonctivites correspondantes aux intervalles d'écarts thermiques positifs par mois au printemps sur la période 2003-2015

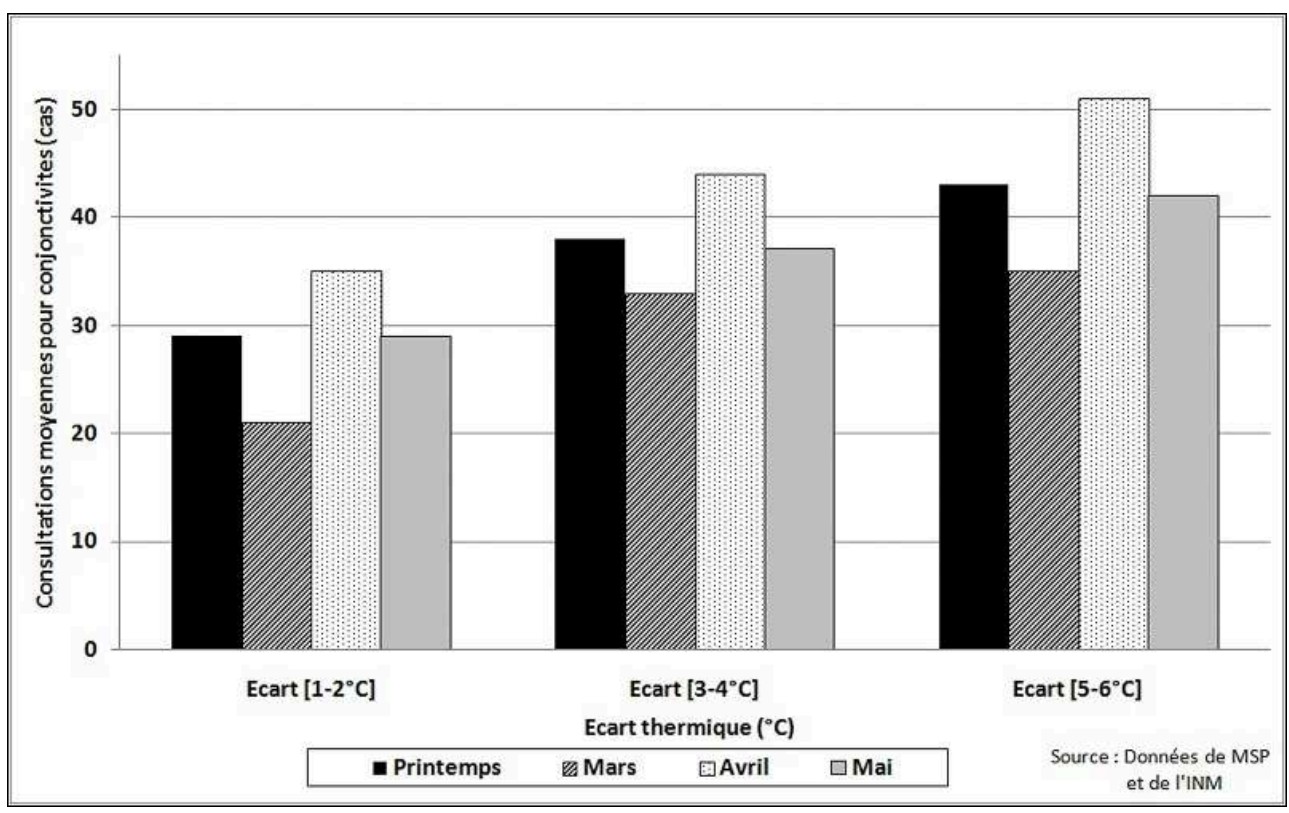

Source: Données MSP et INM. Auteur : M. Jarraya.

Les consultations pour conjonctivites sont plus importantes au printemps qu'en hiver. Le type ou l'origine des conjonctivites expliquent-ils cette recrudescence notable au printemps? Nos entretiens avec les médecins des CSB ainsi qu'avec des patients révèlent que les conjonctivites diagnostiquées sont à dominante allergique. Il s'agit donc d'un changement au niveau du tableau clinique : les conjonctivites infectieuses prédominantes en hiver régressent au profit des types allergiques au printemps. Outre le fait qu'elle résulte d'une allergie et qu'elle constitue par conséquent une maladie indépendante, la conjonctivite devient un symptôme d'une allergie respiratoire (Jarraya et Beltrando, 2015). Le pollen végétal est alors incriminé, puisque le printemps représente la saison de floraison végétale à Sfax. Compte tenu de son pouvoir allergisant élevé, le pollen de l'olivier est responsable de la montée des allergies respiratoires au printemps à Sfax (Jarraya, 2009). Plusieurs recherches ont mis l'accent sur les atteintes allergiques liées au pollen de l'olivier dans les pays méditerranéens (Demoly et al., 2005; Yangui et al., 2018). Nos entretiens avec des médecins pneumologues et allergologues ont confirmé cette responsabilité du pollen de l'olivier. Outre l'adoucissement thermique qui relâche l'activité virale au printemps, le contexte climatique conditionne la propagation du pollen dans l'air. Nous chercherons donc à déterminer cet effet climatique, et ce en dégageant certains aspects météopathologiques printaniers.

\section{Météopathologie printanière des conjonctivites : co-morbidité et contenu aérobiologique en question}

Le choix du mois d'avril est justifié par le fait qu'il connaît la morbidité maximale liée aux conjonctivites. En outre, il constitue la phase de floraison végétale de l'olivier. Le choix de notre corpus de travail (deux situations : avril 2003 et 2012) est justifié par des écarts thermiques assez bas observés dans la situation d'avril 2012, ce qui ne permet 
pas d'illustrer les aspects déduits à l'échelle moyenne de la période (2003-2015). Le recours à la deuxième situation (avril 2003) est susceptible de montrer l'impact de l'amplification de l'écart thermique sur cette morbidité ainsi que l'effet prévisible des situations atmosphériques prédominantes sur le contenu pollinique de l'air.

Les jours les plus doux représentent $43,3 \%$ des jours en avril 2003 et $26,6 \%$ des jours en avril 2012 enregistrant un écart thermique variant de $1^{\circ} \mathrm{C}$ à $6^{\circ} \mathrm{C}$. Un décalage temporel positif de 1 jour a été effectué entre l'écart thermique enregistré dans une journée donné $(\mathrm{J})$ et la consultation journalière pour conjonctivites enregistrée le lendemain $(\mathrm{J}+1)$.

29 Nous notons la prédominance de l'écart $1^{\circ} \mathrm{C}$ qui a été enregistré dans $62 \%$ des jours pendant les deux séquences. Les consultations pour conjonctivites correspondant aux écarts thermiques augmentent en concordance avec la douceur thermique. Même si les écarts thermiques positifs enregistrés en avril 2012 ne dépassent pas $2^{\circ} \mathrm{C}$ le 23 avril (illustration 12B), nous remarquons que les consultations pour conjonctivites sont généralement plus élevées (par exemple 35 cas le 24 avril) par rapport à la morbidité moyenne des jours enregistrant des écarts thermiques négatifs ( 28 cas). Cependant, les écarts thermiques peuvent atteindre $6^{\circ} \mathrm{C}$ en avril 2003. Nous observons que les consultations correspondant aux écarts $\left[3-4^{\circ} \mathrm{C}\right]$ sont largement supérieures à celles qui se rapportent aux écarts $\left[1-2^{\circ} \mathrm{C}\right]$. Par exemple, les consultations ( 32 cas) du 25 et 26 avril 2003, qui enregistrent des écarts respectifs de $1^{\circ} \mathrm{C}$ et $2^{\circ} \mathrm{C}$, sont inférieures à celles correspondant aux 27 et 28 avril 2003 ( 38 et 46 cas) qui expriment des écarts de $3^{\circ} \mathrm{C}$. La décélération des consultations est remarquable, car l'accroissement de l'écart thermique les 29 et 30 avril à $6^{\circ} \mathrm{C}$ est liée à une à une légère diminution des consultations (respectivement 45 et 41 cas) (illustration 12B). Cela peut refléter le rapport entre la diminution de la sensibilité des conjonctivites et l'amplification de l'écart thermique. L'étude de l'état journalier de l'atmosphère et de son évolution durant une séquence donnée permet d'expliquer ce décalage variable entre les deux situations d'avril 2003 et 2012.

30 L'analyse de l'évolution de la situation météorologique, durant la première séquence $\mathrm{du}$ 23 au 25 avril 2012, 医 qui a connu le seul écart thermique positif $\left(2^{\circ} \mathrm{C}\right.$ survenue le 23 avril 2012) 膯 montre la prédominance des directions des deux quadrants Nord-Est et Sud-Est représentant respectivement $56,2 \%$ et $50 \%$ des observations (illustration $12 \mathrm{~A}$ ). Cela est expliqué par la prédominance des champs de pression contrastés durant cette séquence.

31 Tout d'abord, la carte synoptique du 22 avril 2012 (illustration 12E) révèle qu'une cellule anticyclonique, située à l'Est de la Tunisie, est à l'origine d'un vent atteignant Sfax par l'Est et ESE ( $50 \%$ des observations et d'une vitesse modérée de $3,3 \mathrm{~m} / \mathrm{s}$ ) (illustration 12C). Ensuite, les situations des 23 et 24 avril 2012 montrent un passage à un temps cyclonique (illustrations $12 \mathrm{~F}$ et $12 \mathrm{G}$ ) où le flux du Nord est prédominant (respectivement $50 \%$ des observations et d'une vitesse de $5 \mathrm{~m} / \mathrm{s}$ ) (illustration 12C). La situation se rétablit le 25 avril 2012 et devient de nouveau anticyclonique (illustration 12H), caractérisée par la prédominance de la direction Est (37,5\% des observations) et d'une vitesse de $4 \mathrm{~m} / \mathrm{s}$ (illustration 12C). Cette alternance des situations anticyclonique et dépressionnaire a de faibles impacts sur la morbidité liée aux conjonctivites, car la moyenne de celle-ci durant cette séquence $(32$ cas) est relativement supérieure par rapport à la moyenne des jours enregistrant des écarts thermiques négatifs ( 28 cas) durant ce mois. 
Illustration 12A - Rose des vents du 22 au 25 avril 2012

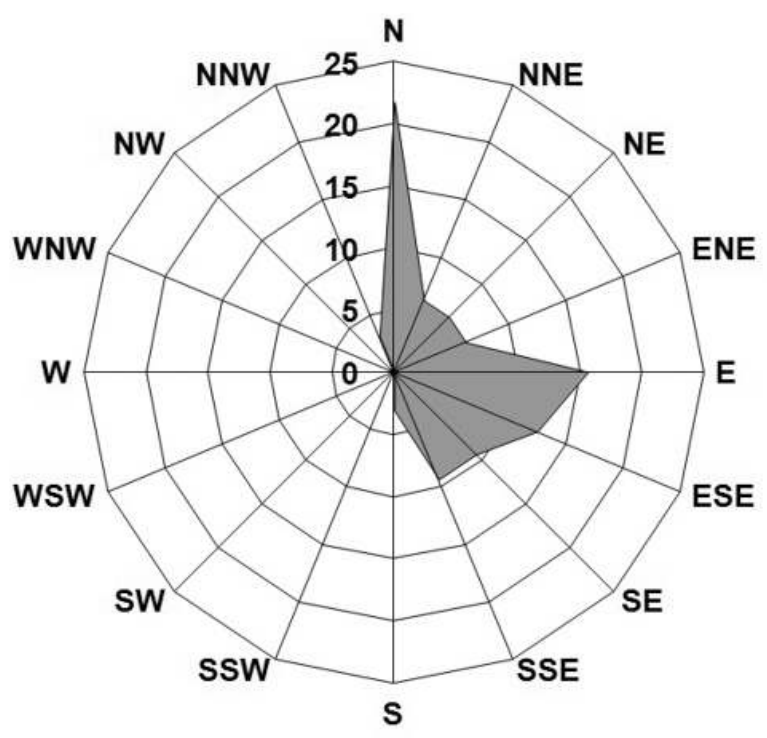

Source: Données INM. Auteur : M. Jarraya.

Illustration 12B - Écarts thermiques positifs et consultations pour conjonctivites correspondantes en avril 2012

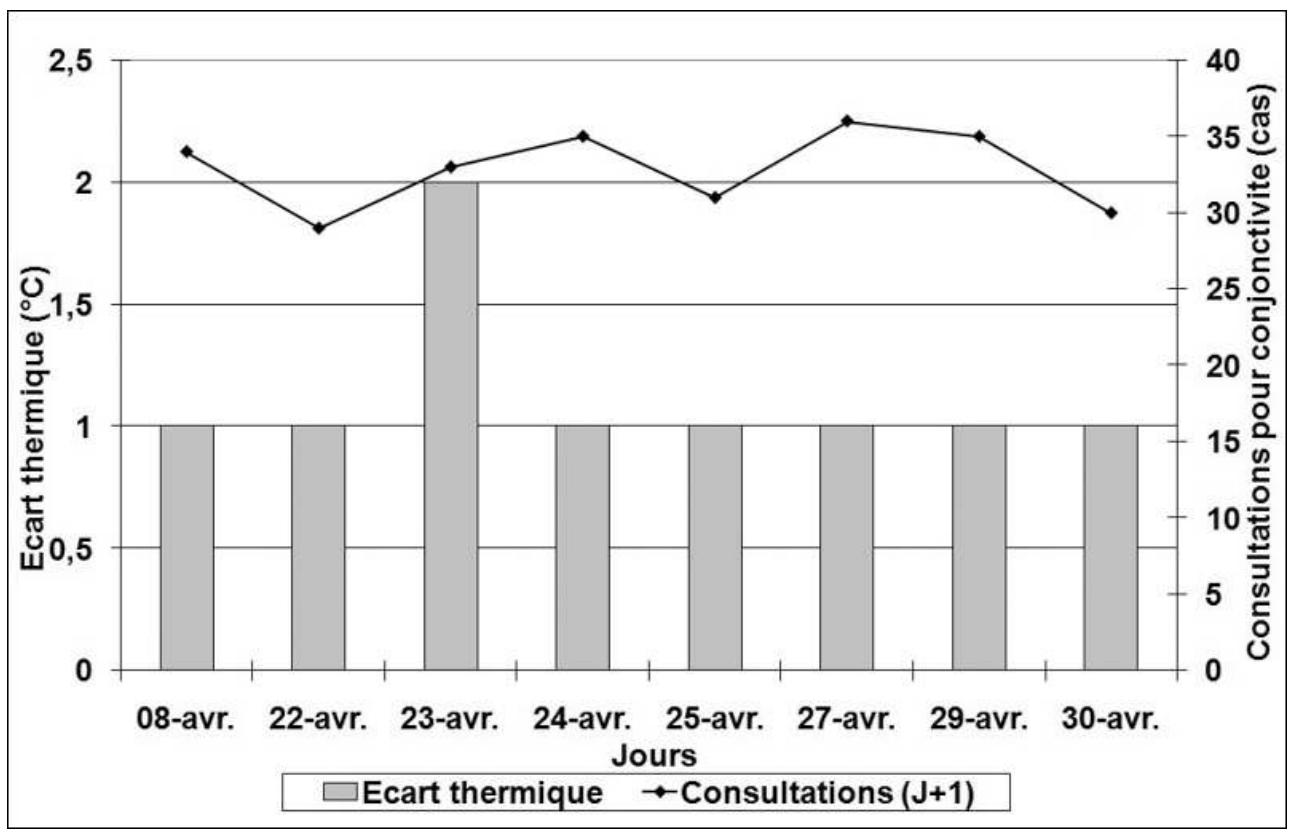

Source : Données MSP et INM. Auteur : M. Jarraya. 
Illustration 12C - Directions du vent et vitesse moyennes associées pendant la séquence 22-25 avril 2012

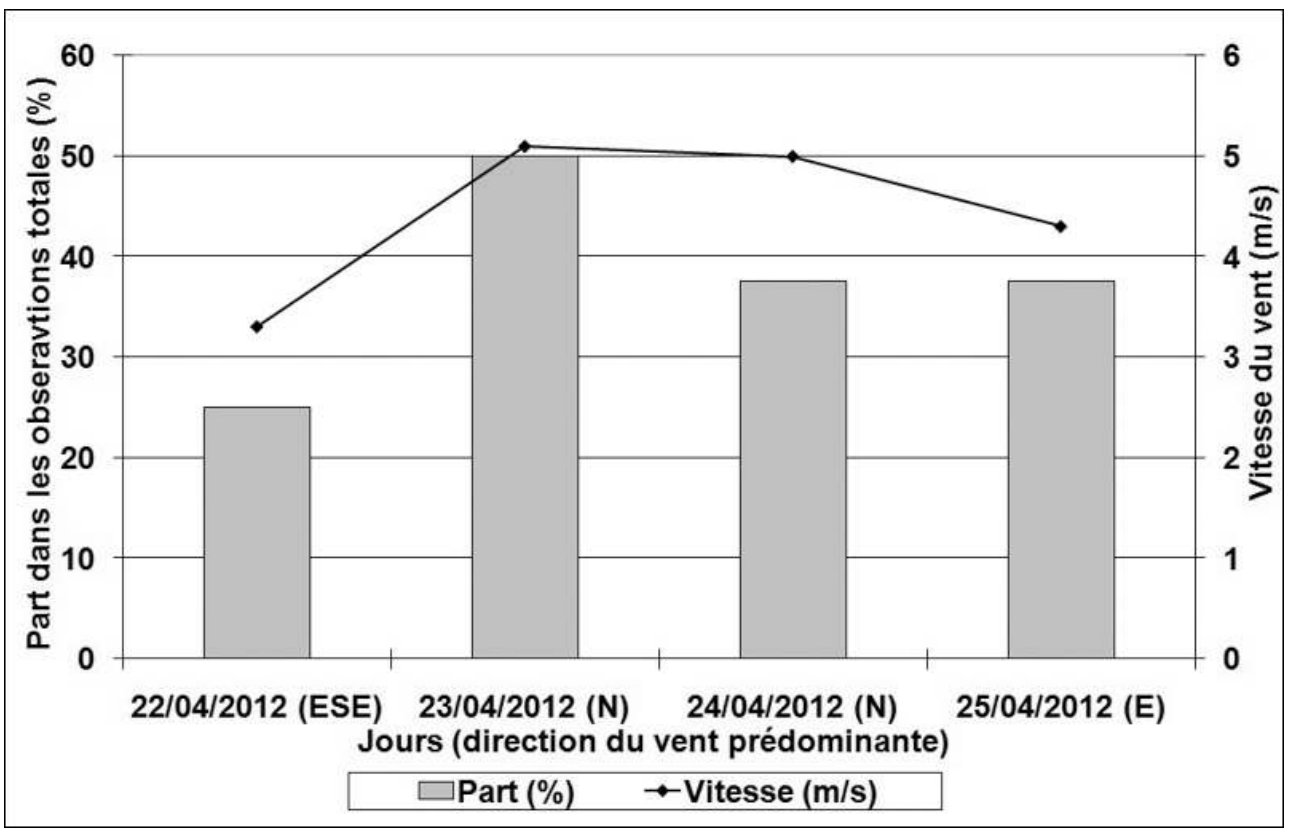

Source: Données INM. Auteur : M. Jarraya.

Illustration 12D - Évolution de l'humidité relative entre les 22 et 25 avril 2012

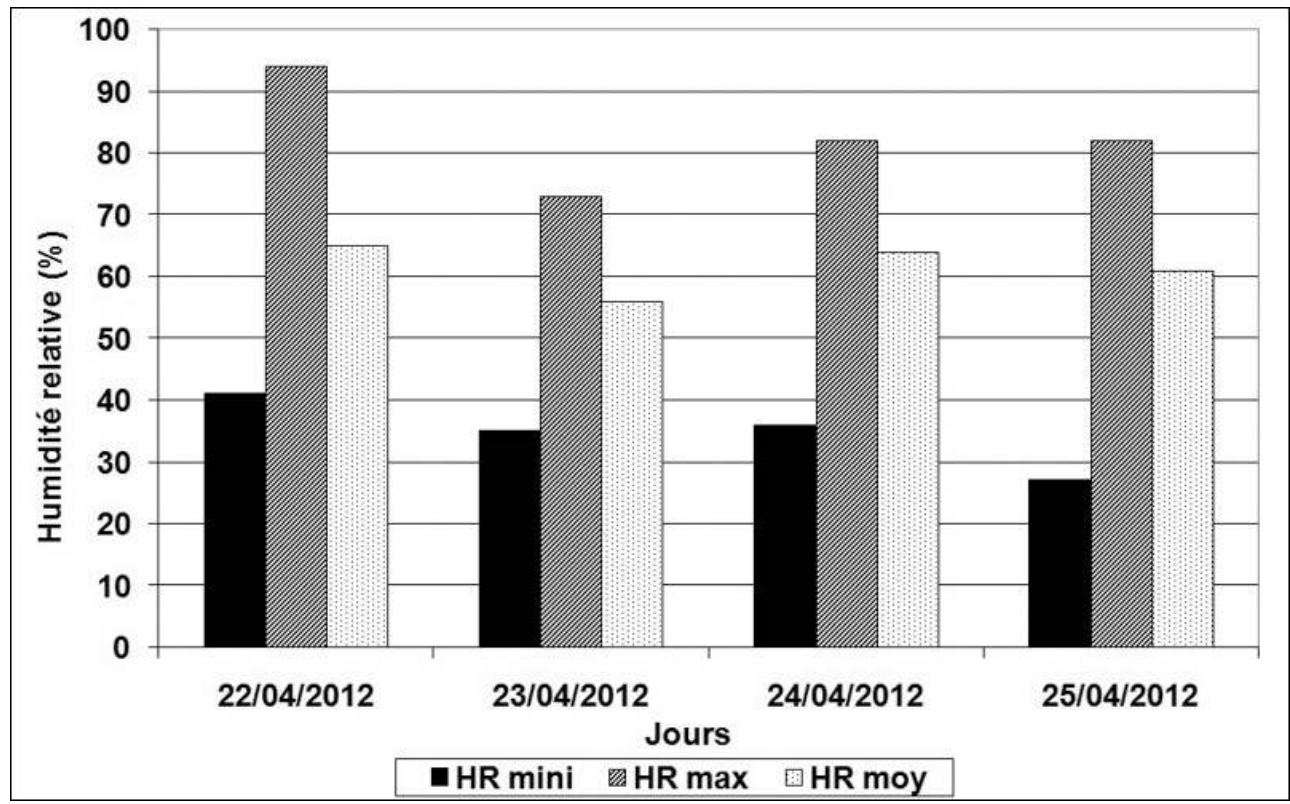

Source : Données INM. Auteur : M. Jarraya. 
Illustration 12E - Situation en surface le 22 avril 2012 à 00h TU

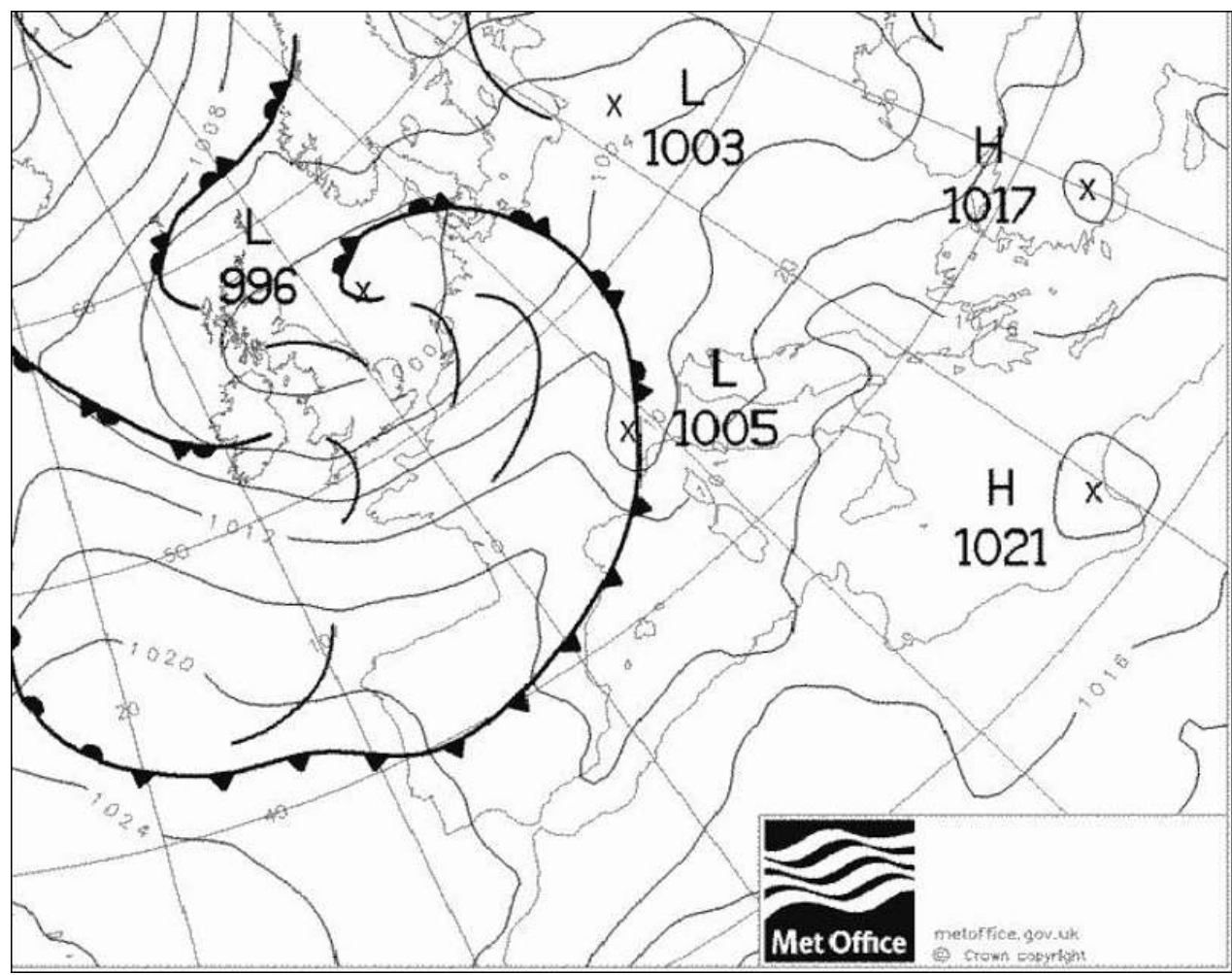

Source: www.metoffice.com. Auteur: M. Jarraya.

Illustration 12F - Situation en surface le 23 avril 2012 à 00h TU

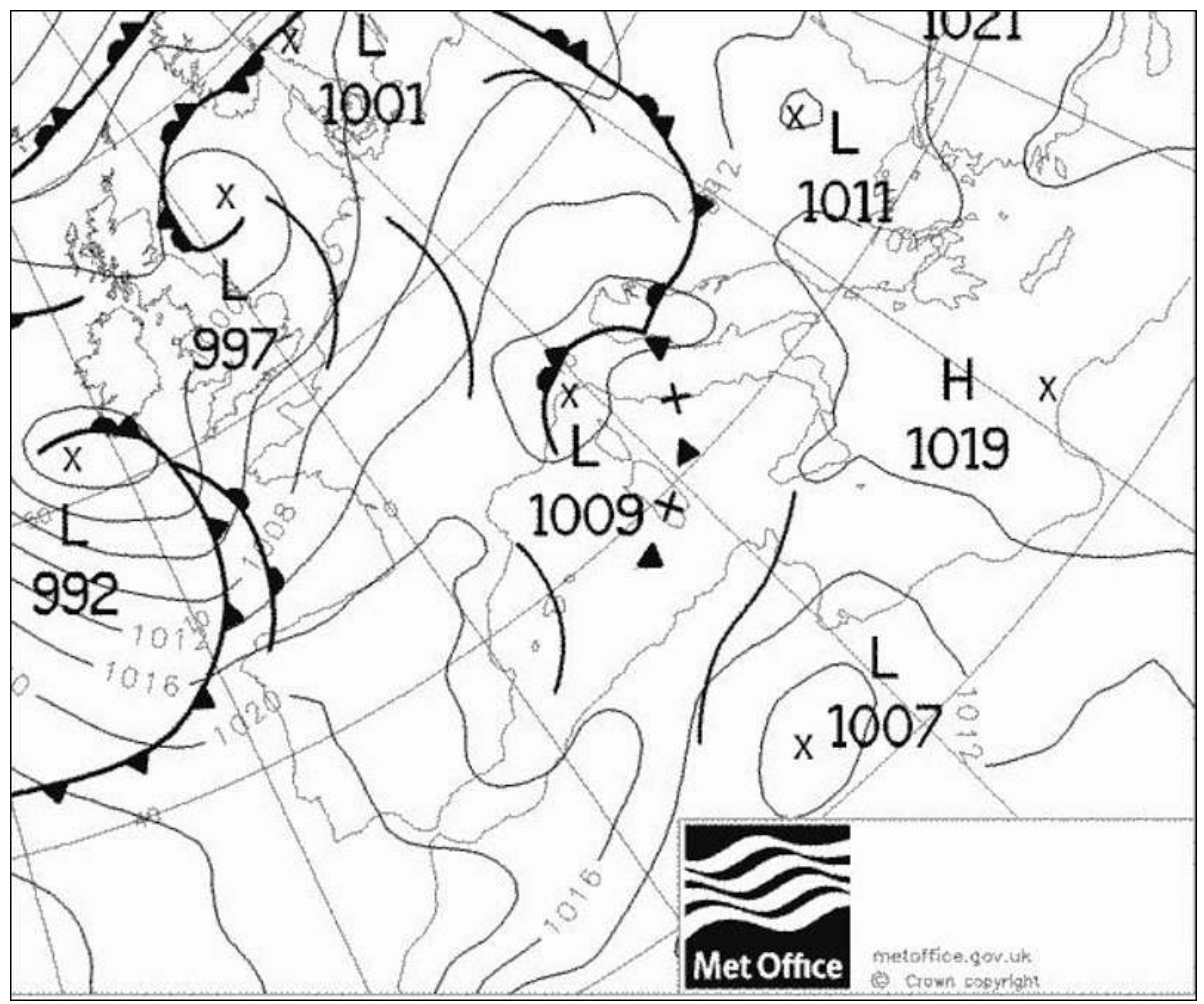

Source : www.metoffice.com. Auteur : M. Jarraya. 
Illustration 12G - Situation en surface le 24 avril 2012 à $00 \mathrm{~h}$ TU

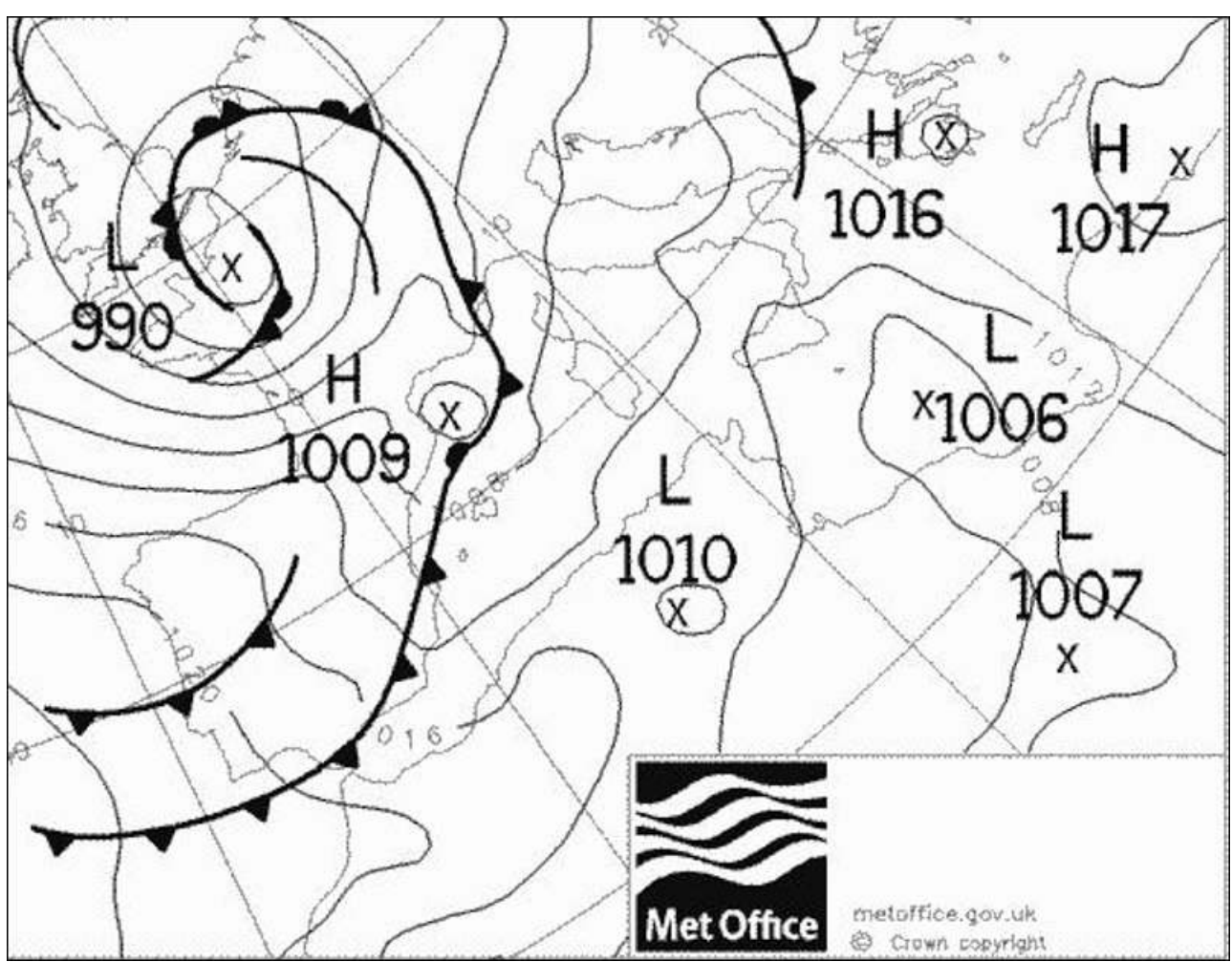

Source: www.metoffice.com. Auteur: M. Jarraya.

Illustration 12H - Situation en surface le 25 avril 2012 à $00 \mathrm{~h}$ TU

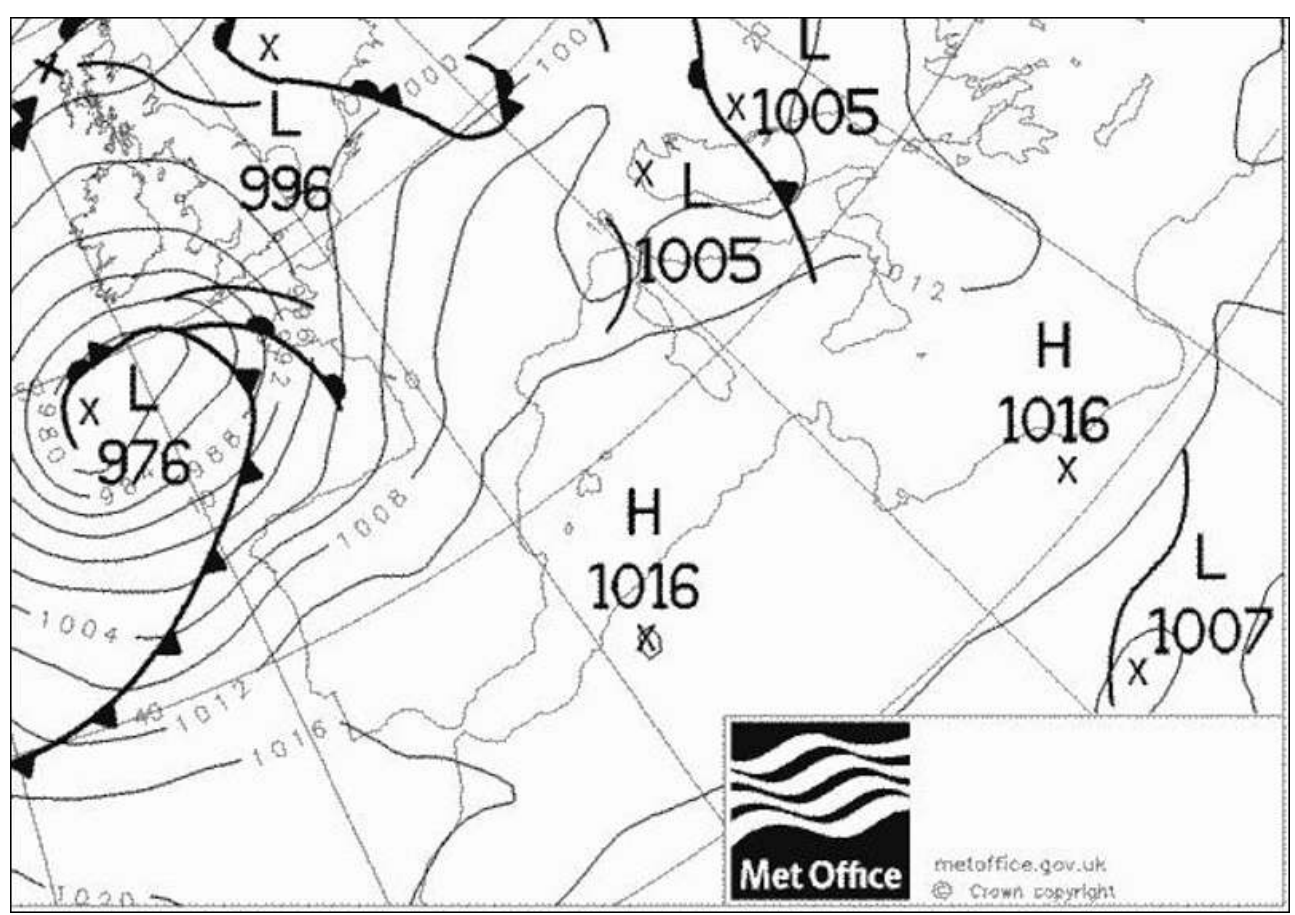

Source: www.metoffice.com. Auteur : M. Jarraya. 
En outre, cette alternance n'a pas induit un véritable changement thermique, ce qui explique les écarts thermiques faibles (de 1 à $2^{\circ} \mathrm{C}$ ). Cela est associé à des niveaux d'humidité assez élevés (moyenne supérieure à $60 \%$ ) (illustration 12D), ce qui n'a pas apparemment de véritables effets directs sur la morbidité liée aux conjonctivites mais touche l'agent externe qui cause l'affection, à savoir le pollen. Même si nous ne disposons d'aucune information sur le contenu pollinique de l'air à Sfax, la littérature nous apprend que la pollinisation est tributaire de l'humidité de l'air et de la vitesse du vent.

Si l'humidité est élevée, le grain de pollen devient plus lourd et donc difficile à être transporté par le vent. En outre, la forte concentration de l'air en pollen est plus importante en cas d'un vent modéré qu'en cas d'un vent faible ou fort (Laiidi, 1999). La succession des situations atmosphériques, marquées par la prédominance des vents de directions maritimes (du NNE à l'Est pour le quadrant Nord-Est et de l'Est à SE pour le quadrant Sud-Est), explique cette humidité élevée (atteignant $94 \%$ la nuit du 22 avril et $82 \%$ les nuits des 24 et 25 avril 2012) (illustration 12D) mais aussi théoriquement, le faible apport en pollen, puisque leurs vitesses qui sont assez actives (supérieures à $4,5 \mathrm{~m} / \mathrm{s}$ ) ne brassent pas la couverture végétale périphérique de l'agglomération dominée par l'oliveraie. Cela justifie la légère augmentation des consultations pour conjonctivites.

Durant la deuxième séquence du 27 au 30 avril 2003, le temps prédominant est anticyclonique. Cela est expliqué par l'installation des cellules anticycloniques à l'Est de

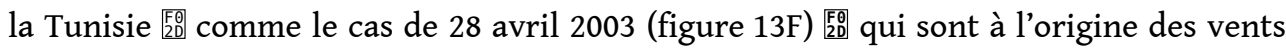
Est, ESE, SE et S (illustration 13A). Vu leur origine maritime, les masses d'air associées à ces vents sont tièdes. Cela influence les écarts thermiques journaliers par rapport à la moyenne thermique mensuelle qui varient de $3^{\circ} \mathrm{C}$ à $6^{\circ} \mathrm{C}$ (illustration 13B). La persistance d'un temps anticyclonique, caractérisé par un adoucissement thermique important et par une vitesse du vent modérée (une vitesse moyenne de $3 \mathrm{~m} / \mathrm{s}$ durant la séquence), offre les conditions favorables aux conjonctivites d'origine allergique.

Notre séquence réunit les conditions propices à une forte activité pollinique et éventuellement à une montée au niveau de la morbidité liée aux conjonctivites. En effet, le temps est anticyclonique, il est associé à un ciel clair, à une humidité diurne faible (36\% en moyenne sur la séquence) (illustration 13D) et à des directions du vent qui brassent la campagne environnante de l'agglomération comme le W, NNE, SE, et $\mathrm{S}$ qui soufflent selon une vitesse moyenne variant de 3 à $4 \mathrm{~m} / \mathrm{s}$ (illustration 13C). Cela aide au transport du pollen loin de son lieu de production (la campagne) vers l'agglomération par le biais du vent, surtout pendant la journée. Cette forte exposition de la population vulnérable au pollen explique des consultations plus élevées pour conjonctivites. 
Illustration 13A - Rose des vents du 27 au 30 avril 2012

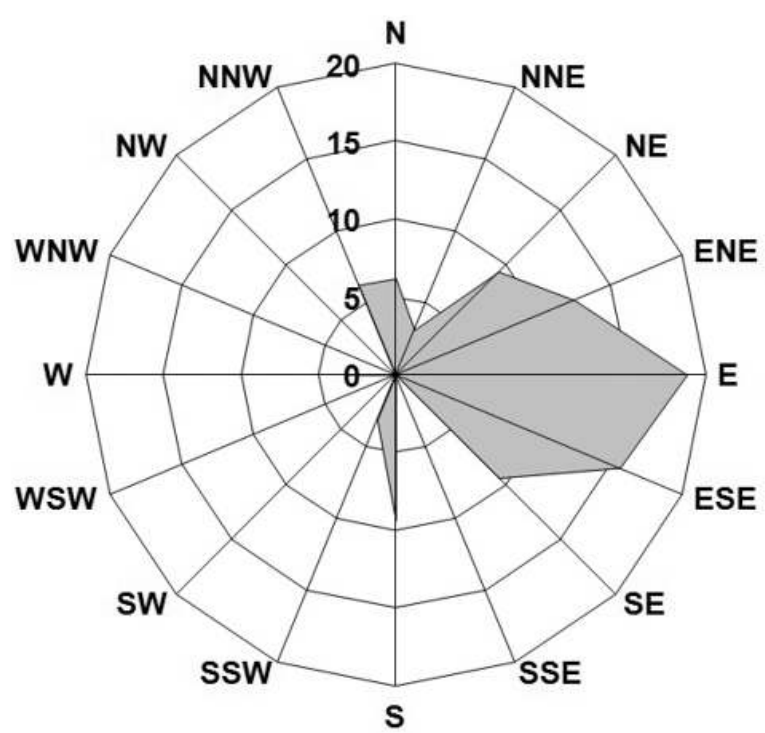

Source : Données INM. Auteur : M. Jarraya.

Illustration 13B - Écarts thermiques positifs et consultations pour conjonctivites correspondantes en avril 2003

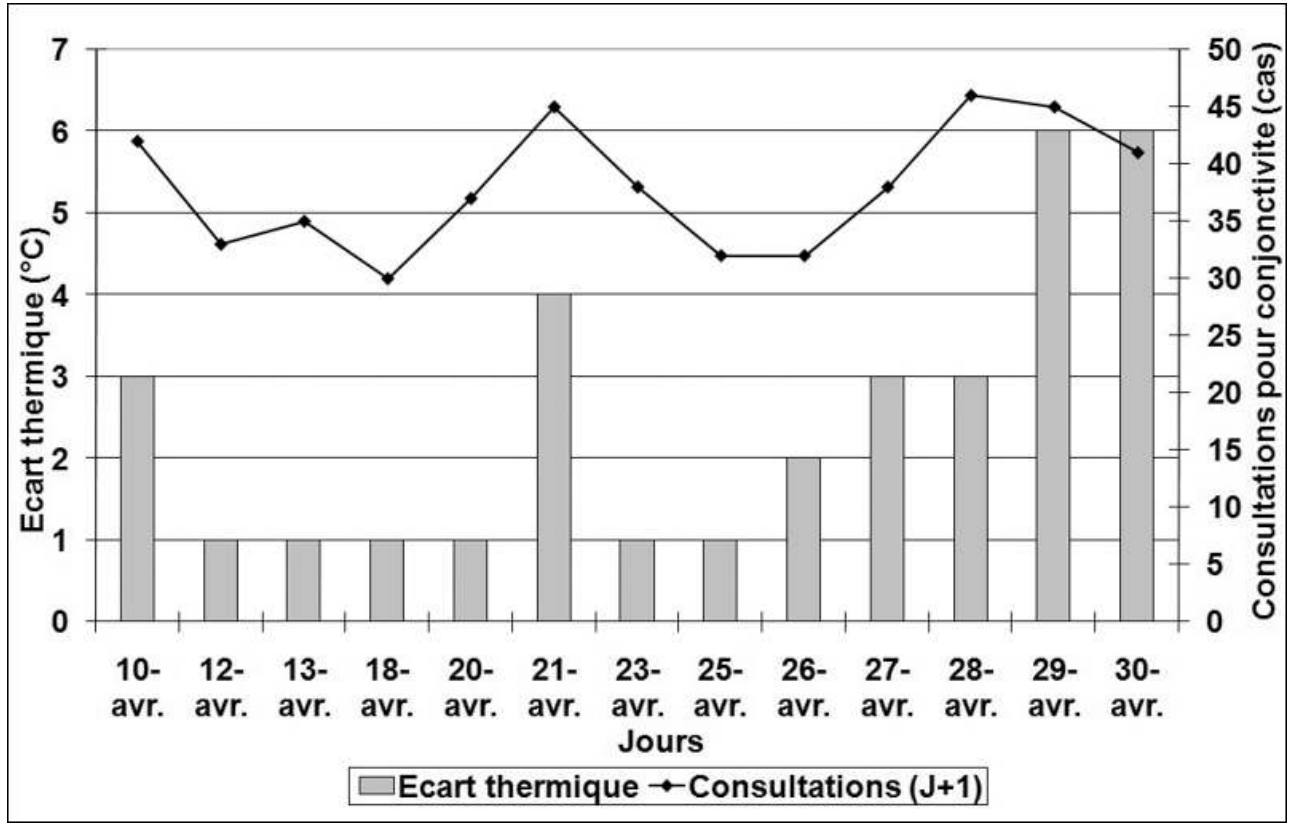

Source : Données MSP et INM. Auteur : M. Jarraya. 
Illustration 13C - Directions du vent et vitesse moyennes associées pendant la séquence 27-30 avril 2003

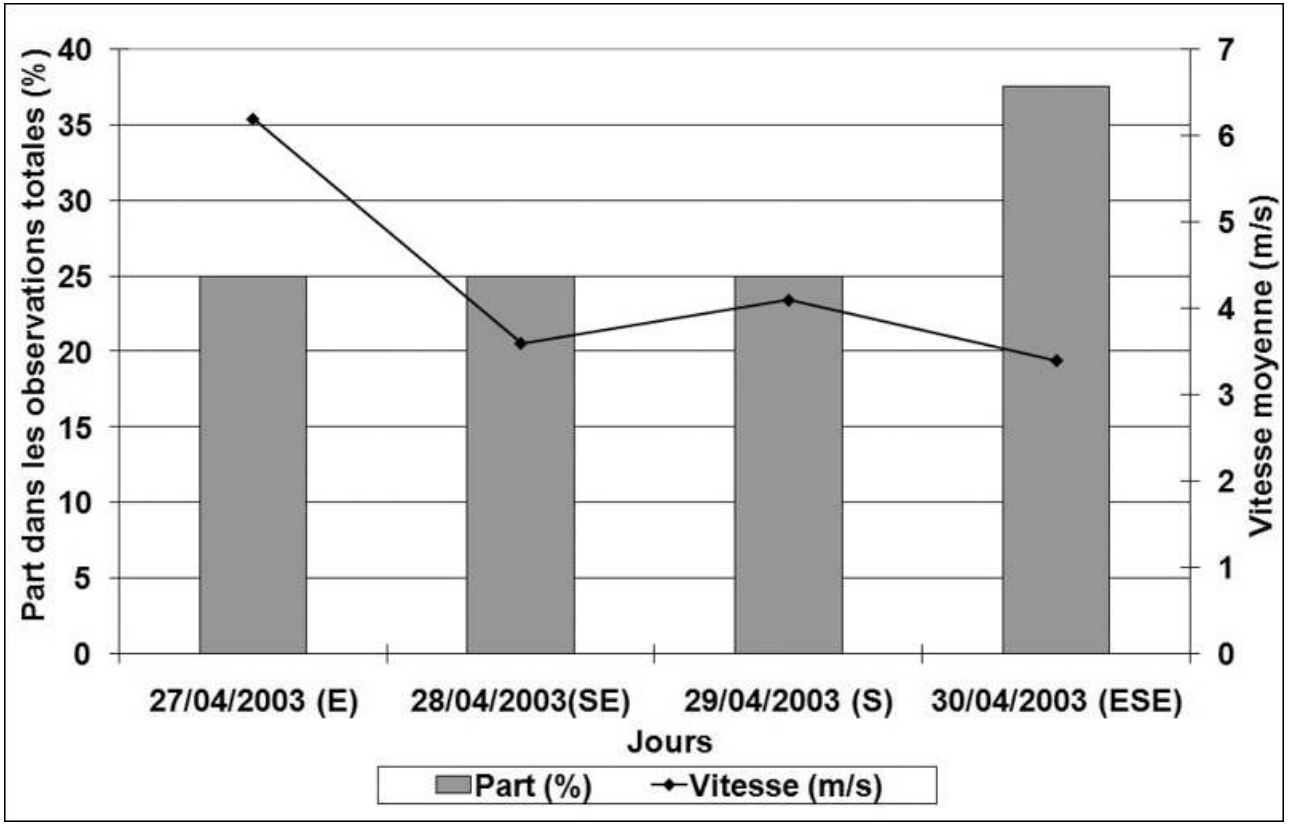

Source : Données INM. Auteur : M. Jarraya.

Illustration 13D - Évolution de l'humidité relative entre les 27 et 30 avril 2003

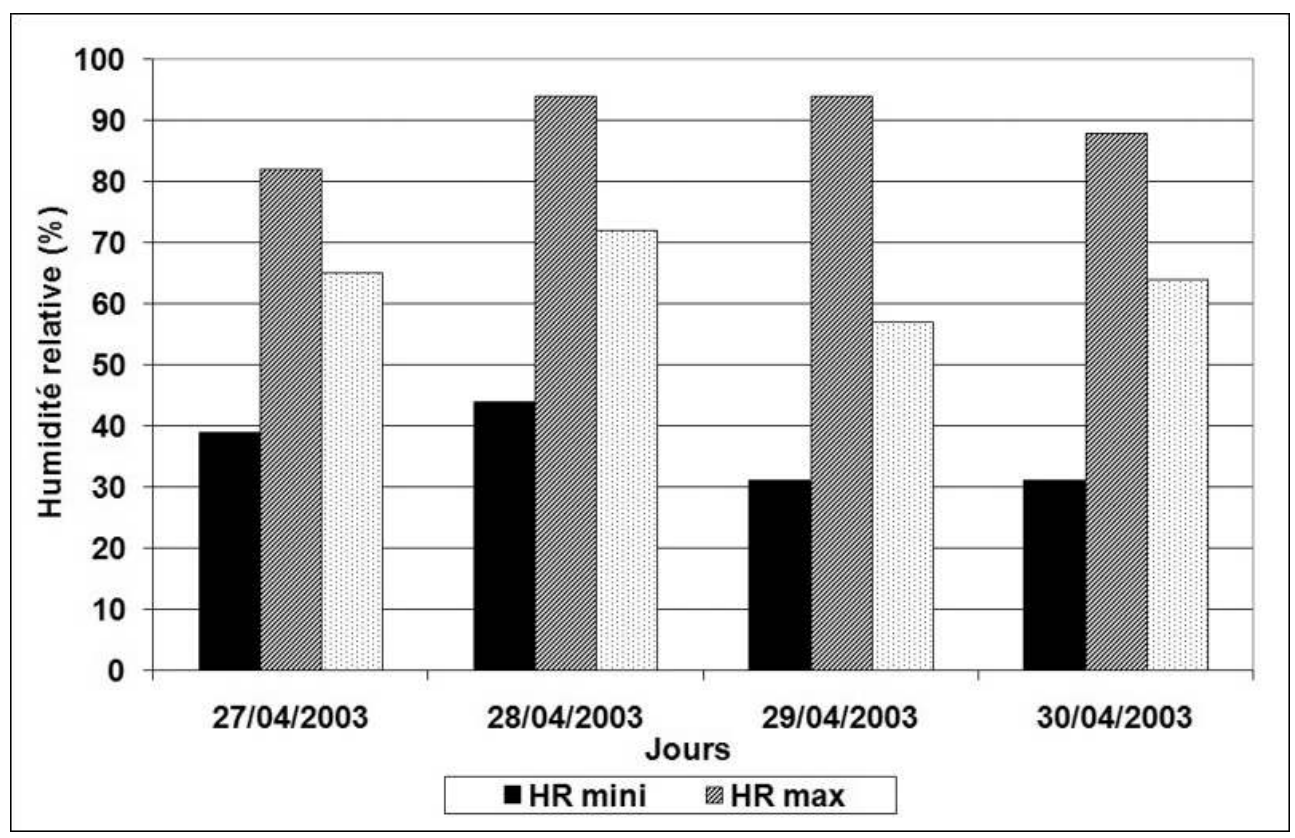

Source: Données INM. Auteur: M. Jarraya. 
Illustration 13E - Situation en surface le 27 avril 2003 à 00h TU

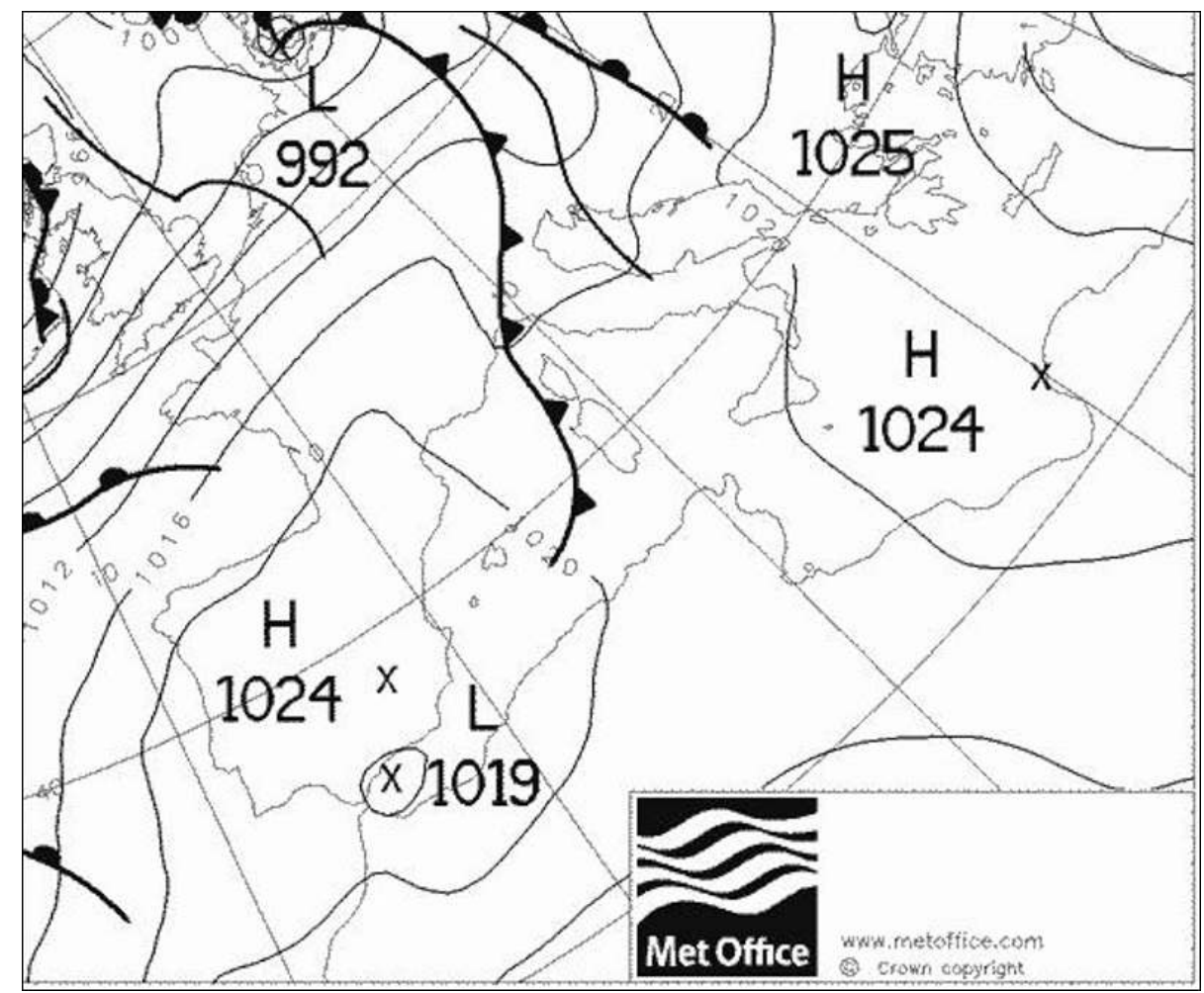

Source : www.metoffice.com. Auteur: M. Jarraya.

Illustration 13F - Situation en surface le 28 avril 2003à 00h TU

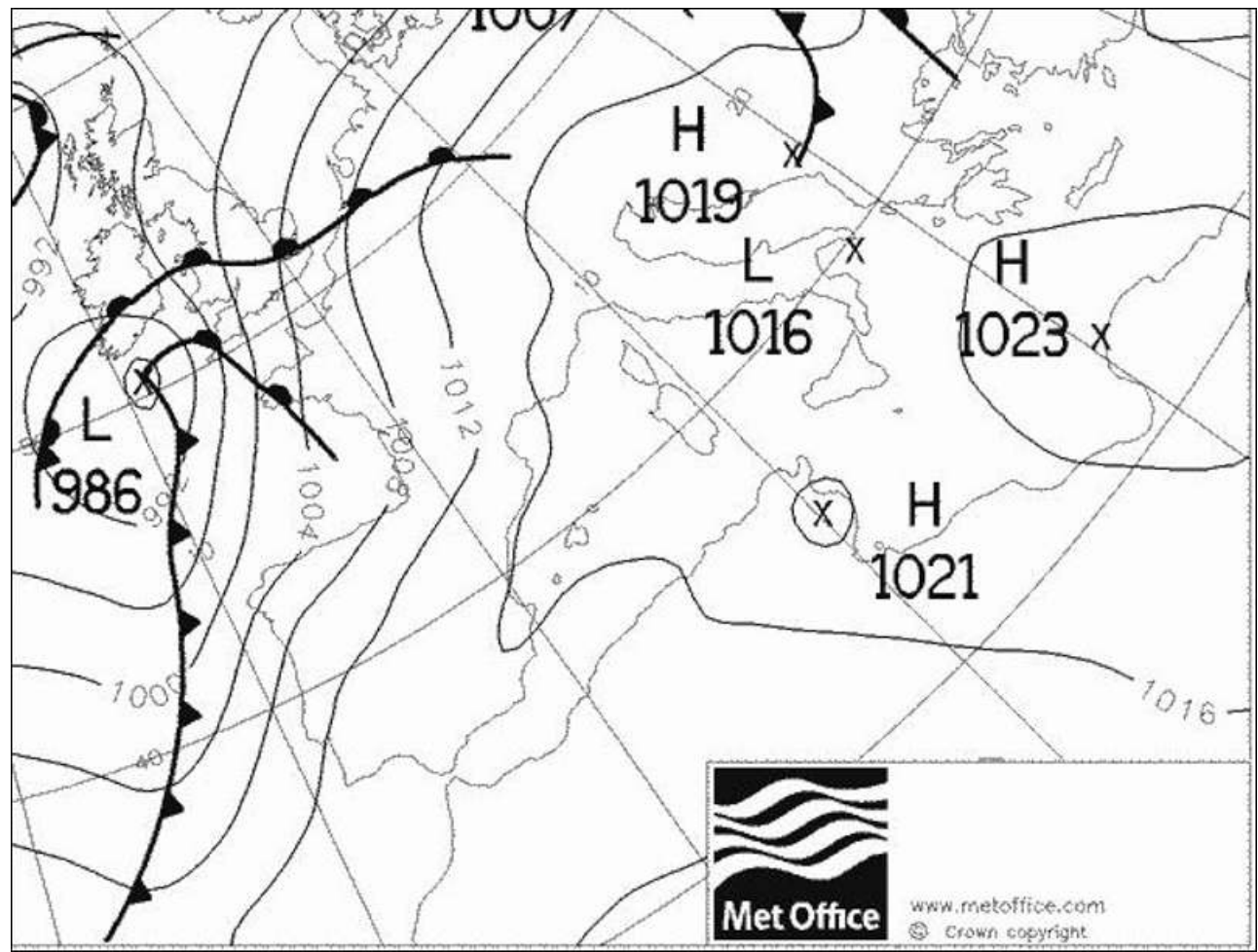

Source : www.metoffice.com. Auteur : M. Jarraya. 
Illustration 13G - Situation en surface le 29 avril 2003 à 00h TU

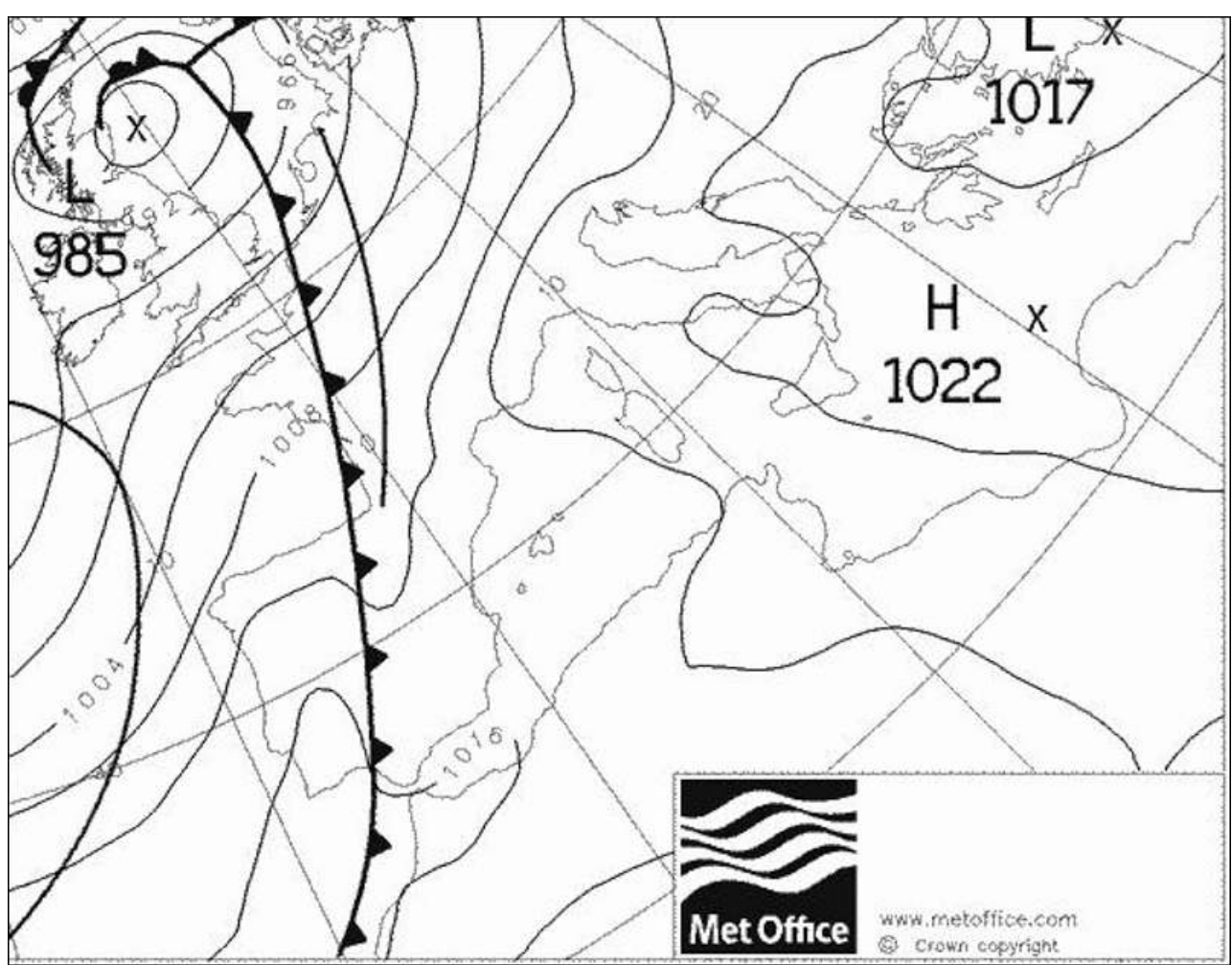

Source : www.metoffice.com. Auteur: M. Jarraya.

Illustration $13 \mathrm{H}$ - Situation en surface le 30 avril 2003 à $00 \mathrm{~h}$ TU

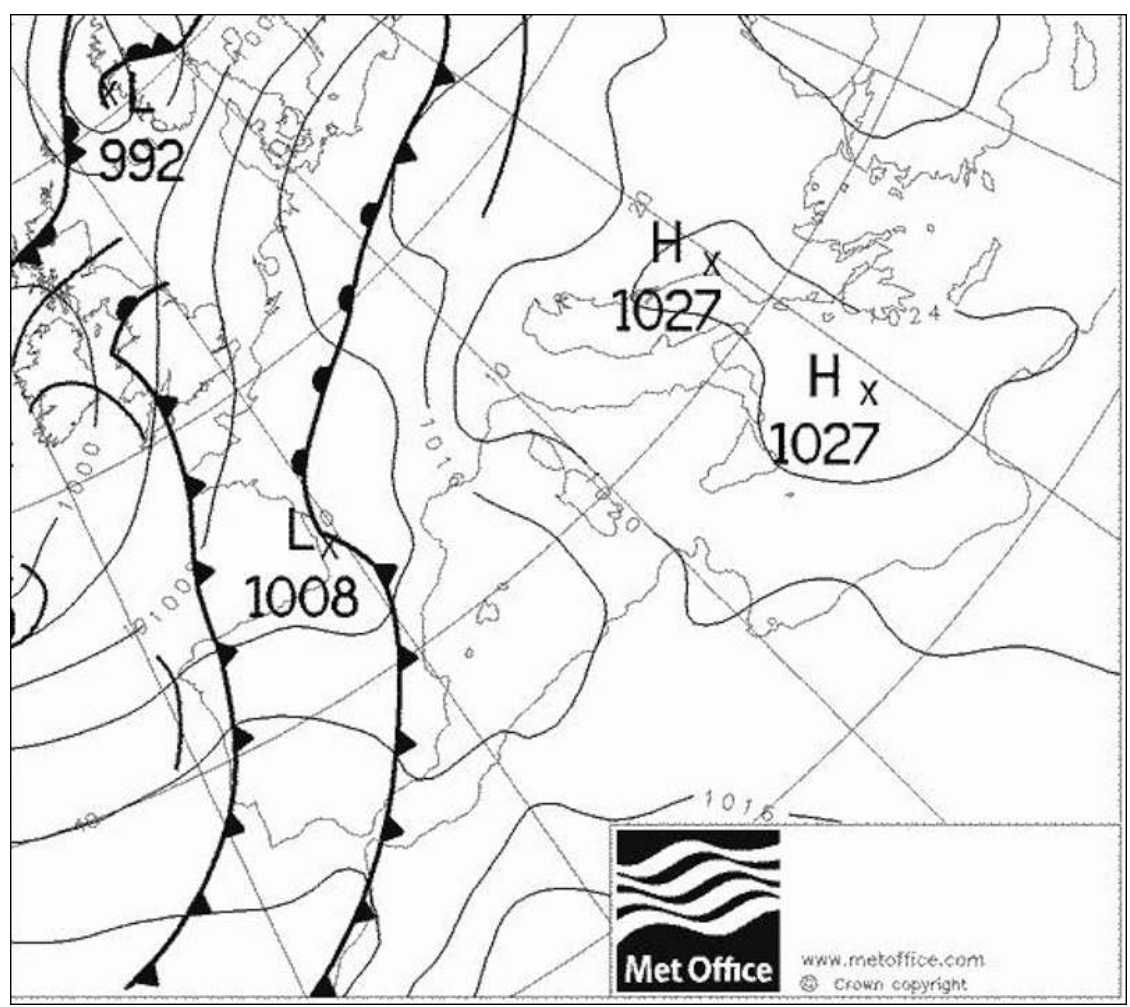

Source : www.metoffice.com. Auteur: M. Jarraya. 
36 À titre d'exemple, l'accentuation de l'écart thermique de $1^{\circ} \mathrm{C}$ à $3^{\circ} \mathrm{C}$ est associée à une hausse au niveau des consultations pour conjonctivites de 32 cas à 46 cas entre le 26 et le 28 avril 2003. En outre, nous observons une fréquence des directions SE, NE, SE qui soufflent à une vitesse modérée $(3 \mathrm{~m} / \mathrm{s})$ capable de transporter le pollen de l'olivier et de charger l'air de l'agglomération. Nous remarquons enfin la décélération, voire la diminution de la morbidité liée aux conjonctivites observée le 30 avril 2003 (respectivement $41 \mathrm{cas}$ ), malgré l'amplification de l'écart thermique à $6^{\circ} \mathrm{C}$ et la persistance du temps anticyclonique. Nous suggérons que l'activité allergique atteint son maximum avec un écart compris entre $3^{\circ} \mathrm{C}$ et $4^{\circ} \mathrm{C}$ et donc, au-delà de cet intervalle le rythme décélère ou se stabilise.

Il ressort de notre enquête déroulée du 06 au16 avril 2015 que $84 \%$ des consultations pour asthme (un effectif total de 114 patients) dans les CSB sont attribuées aux allergènes végétaux. En outre, $90 \%$ de ces personnes déclarent le pollen de l'olivier comme l'allergène responsable de leur asthme. La quasi-totalité ( $9 \%$ de ces personnes affirme que la conjonctivite est un symptôme fréquent qui accompagne leur asthme au printemps. Ils soulignent également que cette association asthme-conjonctivite affecte sensiblement leur bien-être : respiration sifflée, toux, éternuement, écoulement nasal, picotement des yeux... (Jarraya, 2018b).

\section{Discussion}

Les 29 centres de soins bien répartis dans l'espace permettent de collecter des informations représentatives de l'agglomération de Sfax. Les données épidémiologiques ne fournissent aucune information sur le type de conjonctivite. C'est à travers nos entretiens avec le corps médical et les patients que nous sommes arrivés à distinguer l'origine des conjonctivites et son association avec d'autres pathologies en hiver et au printemps. Si nous nous sommes basés sur les confirmations médicales et les déclarations des patients pour identifier l'origine des conjonctivites et leurs aspects météopathologiques, l'utilisation des informations relatives au pollen de l'olivier à Sfax est indispensable pour déterminer sa part dans la réactivation des allergies respiratoire et oculaire. Outre les facteurs liés à l'environnement extérieur (climat, pollen, agent infectieux), d'autres déterminants sociaux interviennent pour justifier cette morbidité. Nous soulignons ici l'apport majeur de notre enquête dans les CSB qui nous a permis de déterminer l'effet du pollen et d'autres facteurs supplémentaires favorisant la survenue des conjonctivites.

39 Vu que les CSB drainent $60 \%$ de la population de l'agglomération, nos résultats seront généralisés avec prudence, car une partie consulte chez les médecins de libre pratique. De plus, le facteur de l'automédication réduit véritablement les consultations, car les dangers des conjonctivites sont le plus souvent sous-estimés. Dans ce même contexte de représentativité limitée, l'enquête établie sur une courte période ( 10 jours) et dans $10 \mathrm{CSB}$, malgré l'importance des informations collectées, ne peut pas être considérée comme très représentative.

Une recrudescence hivernale de la morbidité liée aux conjonctivites ainsi que sa croissance printanière permet de suggérer un premier effet de la fraîcheur et un deuxième effet plus fort de la douceur sur la réaction des conjonctivites, face au changement de son environnement atmosphérique extérieur entre les deux saisons. 
Compte tenu de la localisation littorale de Sfax, l'effet de l'humidité est également non négligeable. L'intégration des situations atmosphériques qui conditionnent la fraîcheur et la douceur aide à comprendre le contexte dans lequel cette morbidité se développe. Telle est notre problématique qui a abouti à dégager certains aspects météopathologiques spécifiques à Sfax dans les deux saisons. Cependant, l'humidité de l'air constitue un facteur permanent favorisant la vulnérabilité de l'œil aux conjonctivites ainsi que l'effet supplémentaire du pollen au printemps.

41 Si notre objectif est de vérifier la similarité des tendances dégagées à l'échelle mensuelle entre les mois hivernaux et printaniers (au niveau de l'accentuation de la fraîcheur et de la douceur) et leur impact sur la morbidité liée aux conjonctivites, une attention doit être aussi accordée à la quantification de la consultation: est-elle proportionnelle avec l'intensification de la fraîcheur ou la douceur? Dans ce contexte, les ambiances thermiques fraîches en hiver et douces au printemps ne présentent-elles pas les mêmes modes de réaction avec l'organisme humain? En effet, la réaction est plus rapide avec la fraîcheur en hiver qu'avec la douceur printanière. Cela peut être expliqué par l'agent infectieux (disposant d'une transmission inter-humaine potentielle et de sa sensibilité à l'environnement extérieur) en hiver et allergique au printemps.

Le recours à quelques situations pour montrer l'impact des conditions atmosphériques sur la morbidité liée aux conjonctivites est insuffisant pour des raisons de représentativité. C'est pour cela que nous avons analysé la situation à l'échelle de l'ensemble de la période. Il est intéressant de rappeler que d'autres facteurs, qui ne sont pas étudiés dans ce travail, jouent le rôle des facteurs de confusion. Tout d'abord, l'hypersensibilité de l'œil à certains produits cosmétiques et médicaments peut être à l'origine d'une conjonctivite allergique. Ensuite, la chaleur et la transpiration peuvent fragiliser la conjonctive de l'œil. Enfin, la pollution atmosphérique induite par l'activité industrielle et de la circulation automobile intense dans la ville de Sfax et l'exposition à certaines fumées et odeurs peuvent irriter l'œil chez les personnes sensibles.

\section{Conclusion}

43 Le contexte climatique conditionne le paysage épidémiologique saisonnier des conjonctivites. L'origine de l'agent responsable de l'affection, infectieux et/ou allergique, détermine tout d'abord l'interaction avec l'environnement atmosphérique extérieur et ensuite le niveau d'" agression» de l'organisme humain. Des aspects météopathologiques dégagés au niveau de la morbidité liée aux conjonctivites à Sfax permettent d'attribuer aux situations atmosphériques en hiver et au printemps un effet capital sur le motif prédominant infectieux et/ou allergique des consultations médicales.

Les situations atmosphériques les plus fréquentes, qui conditionnent les propriétés des paramètres climatiques, peuvent impulser des types de conjonctivites plus que d'autres. Les situations anticycloniques instaurent des conditions favorables aux conjonctivites d'origine infectieuse prédominantes en hiver. D'autres situations dépressionnaires plus ou moins humides peuvent favoriser des conjonctivites allergiques influencées également par les conditions d'habitat, le cadre et le niveau de vie des individus. Si le motif infectieux régresse au printemps, le contexte climatique influence le contenu pollinique de l'air et par conséquent la réactivation des allergies. Les situations anticycloniques s'avèrent favorables à une morbidité élevée d'origine 
allergique, dans la mesure où le pollen d'olivier peut, sous un contexte climatique spécifique, se concentrer dans l'air de l'agglomération et donc provoquer des réactions allergiques respiratoire et oculaire au niveau de la population vulnérable.

Bien qu'elles soient banales, les conjonctivites infectieuses peuvent gêner la vie quotidienne des individus et être à l'origine de l'interruption des activités (travail, enseignement, etc.). La connaissance de son interaction avec le contexte climatique, des aspects météopathologiques engendrés et de sa correspondance avec l'adoucissement thermique hiverno-printanier est fortement utile pour prévenir la population à risque et pour envisager la vaccination des personnes allergiques, afin de réduire le niveau de la morbidité liée aux conjonctivites.

\section{BIBLIOGRAPHIE}

Abouda M., Yangui F., Khouani H., Triki M., Charfi M.R., 2014. L'allergie aux moisissures en Tunisie. Revue Française d'Allergologie, vol. 54, n³, p. 273. https://doi.org/10.1016/j.reval. 2014.02.155

Ben Jemaâ I., 2004. Indicateurs hospitaliers de l'activité de l'EPS Hédi Chaker en 2002. Thèse de doctorat, Université de Sfax, Faculté de Médecine, 73 p.

Dalibon P., 2014. Des paupières jusqu'au nerf optique, des affections oculaires diverses. Actualités pharmaceutiques, vol. 53, n 539, p. 16-23.

Demoly P., Godard P., Bousquet J., 2005. Une synthèse sur l'épidémiologie de l'asthme. Revue Française d'Allergologie et d'Immunologie Clinique, $\mathrm{n}^{\circ}$ 45, p. 464-475.

Dowell S., 2001 : Seasonal variation in host susceptibility and cycles of certain infectious diseases. Emerging Infectious Diseases, vol. 7, $\mathrm{n}^{\circ}$ 3, p. 369-374.

Fakhfakh F., 2000. Le tertiaire supérieur à Sfax : Le service médical et l'enseignement supérieur. Thèse de doctorat, Université de Tunis I, Faculté des Sciences Humaines et Sociales, 446 p.

Fedaoui N., Ben Ayed N., Ben Yahia A., Matri L., Nacef L., Triki H., 2017. Aspects épidémiologiques et virologiques de la conjonctivite à adénovirus en Tunisie. Journal Français d'Ophtalmologie, vol. 40, $\mathrm{n}^{\circ} 1$, p. 29-35.

INS (Institut National de la Statistique), 2015. Sfax à travers le recensement général de la population et de l'habitat 2014. Tunis, $186 \mathrm{p}$.

Jammal A., Allard R., Loslier G., 1988. Dictionnaire d'Epidémiologie. Paris, Maloine, 171 p.

Jarraya M., 2009. Biométéorologie de la morbidité respiratoire dans le secteur public de la santé à Sfax. Thèse de doctorat, Université Paris Diderot (Paris 7), 364 p.

Jarraya M., 2012. Ambiances froides et consultations respiratoires dans le secteur public de la santé à Sfax (Tunisie). Cybergeo [En ligne], nº 585. http://cybergeo.revues.org/25032

Jarraya M., Beltrando G., 2013. Les services de soins hospitaliers publics dans l'agglomération de Sfax : spécificités fonctionnelles et pouvoir spatial. EchoGéo [En ligne], $\mathrm{n}^{\circ}$ 26. https:// journals.openedition.org/echogeo/13632 
Jarraya M., Beltrando G., 2015. Hospitalisation cardiovasculaire hivernale à Sfax (Centre-Est de la Tunisie) : Population vulnérable et aspects climato-pathologiques. Actes du XXVIIIe Colloque de l'Association Internationale de Climatologie, Liège, 1-4 juillet 2015, p. 170-175.

Jarraya M., Beltrando G., 2016.

Poussés d'asthmes à Sfax (Tunisie) : aspects multiples de vulnérabilité accrue par le contexte climatique.

Actes du XXIXe Colloque de l'Association Internationale de Climatologie, Besançon-Lausanne, 3-6 juillet 2016, p. 137-142.

Jarraya M., 2016 : Bioclimatologie des infections cutanées mycosiques à Sfax (Centre-Est de la Tunisie).

EchoGéo [En ligne], 38. https://journals.openedition.org/echogeo/14764

Jarraya M., 2017.Risques climato-pathologiques des maladies hydriques à Sfax (Tunisie) : perception de la vulnérabilit épar la population et modalités de gouvernance. Actes du XXXe Colloque de l'Association Internationale de Climatologie, Sfax (Tunisie), 3-6 juillet 2017, p. 121-126.

Jarraya M., 2018a.Froid hivernal et fréquence de la grippe à Sfax (Centre-Est de la Tunisie). Territoires en Mouvement [En ligne], Articles, mis en ligne le 25 janvier 2018. http:// journals.openedition.org/tem/4463

Jarraya M., 2018b.Déterminants socio-environnementaux des disparités de l'asthme dans l'agglomération de Sfax (Centre-Est de la Tunisie). Revue Francophone sur la Santé et les Territoires [En ligne], avril 2018. https://f-origin.hypotheses.org/wp-content/blogs.dir/1946/files/2018/09/ Jarraya-M_RFST_2018.pdf

Karray N., 1996. Le littoral de Sfax et ses enjeux. Revue Tunisienne de Géographie, nº 30, p. 101-121.

Laiidi K., 1999. Eco-épidémiologie des pollinoses en Hautes-Bourgognes. Thèse de doctorat, Université de Bourgogne, Faculté de Médecine, 450 p.

Laaidi M., Chinet T., Aegerter P., 2011. Allergie au pollen, pollution et climat : revue de la littérature. Revue Française d'Allergologie, n 51, p. 622-628.

Leonardi A., Bogacka E., Fauquert J-L. et al. 2014. Allergie oculaire : reconnaître et diagnostiquer les réactions d'hypersensibilité de la surface oculaire. Revue Française d'Allergologie, ${ }^{\circ} 54$, p. 377-388.

Lysaniuk B., 2012. Les catastrophes sanitaires « climato-induites » au XXe siècle : quand soufflent le chaud et le froid en Europe. In Baggio S., Tabeaud M. (ed.), Les catastrophes. Bruxelles, De Boeck.

Mäkinen T., Raija Juvonen K., Jokelainen J. et al., 2009. Cold temperature and low humidity are associated with increased occurrence of respiratory tract infections. Respiratory Medecine, $\mathrm{n}^{\circ} 103$, p. 456-462.

Réseau National de Surveillance Aérobiologique (R.N.S.A.). Site internet : www.pollens.fr

Tang J., 2009. The effect of environmental parameters on the survival of airborne infectious agents. J R Soc Interface, p. S737-S746. DOI : 10.1098/rsif.2009.0227.focus

Thibaudon M., Outteryck R., Lachasse C., 2005. Bioclimatologie et allergie. Revue Française d'Allergologie et d'Immunologie Clinique, $\mathrm{n}^{\circ}$ 45, p. 447-455.

Yangui F., Abouda M., Khouani H., Charfi M.R., 2018. Profils clinique et allergique des pollinoses en Tunisie. Revue Française d'Allergologie [En ligne]. https://doi.org/10.1016/j.reval.2018.01.008 


\section{RÉSUMÉS}

À Sfax, la morbidité liée aux conjonctivites est fortement influencée par le contexte climatique. En effet, la fréquence des consultations pour conjonctivites - enregistrées par les Centres de Santé de Base -, durant la phase hiverno-printanière, va de pair avec l'évolution de la situation thermique. L'analyse de l'accroissement de cette morbidité pendant cette période permet de déterminer des aspects météopathologiques spécifiques, dont le passage de la fraîcheur hivernale à la douceur printanière ainsi que la prédominance d'un type bien déterminé de conjonctivites en fonction de la saison constituent les facteurs majeurs.

The morbidity related to conjunctivitis is influenced by the climatic conditions in Sfax. In fact, the frequency of consultations for conjunctivitis - recorded by Primary Health Care Centers-, during the winter-spring period, correlates with the evolution of the thermal situation. The analysis of the increase in the morbidity rate during this period enables us to determine specific weather-pathological aspects including the transition from winter freshness to spring coolness as well as the predominance of a given type of conjunctivitis in accordance with the season. The latter represent the major factors.

\section{INDEX}

Mots-clés : morbidité, conjonctivite, situation thermique, phase hiverno-printanière, météopathologie, Sfax

Keywords : morbidity, conjunctivitis, thermal situation, winter-spring period, weatherpathology, Sfax

\section{AUTEUR}

\section{MOUNIR JARRAYA}

Mounir Jarraya, jarrayamounir@gmail.com, est maître assistant à l'Université de Sfax, Laboratoire Syfacte. Il a récemment publié :

- Jarraya M., 2018. Froid hivernal et fréquence de la grippe à Sfax (Centre-Est de la Tunisie). Territoires en Mouvement, [En ligne]. http://journals.openedition.org/tem/4463 - DOI : 10.4000/ tem.4463

- Jarraya M., 2018. Déterminants socio-environnementaux des disparités de l'asthme dans l'agglomération de Sfax (Centre-Est de la Tunisie). Revue Francophone sur la Santé et les Territoires, avril 2018, 29 p. https://rfst.hypotheses.org/files/2018/09/Jarraya-M_RFST_2018.pdf

- Rouland B., Jarraya M., 2019. From medical tourism to regionalism from the bottom up: emerging transnational spaces of care between Libya and Tunisia. Journal of Ethnic and Migration Studies [En ligne]. https://doi.org/10.1080/1369183X.2019.1597475 